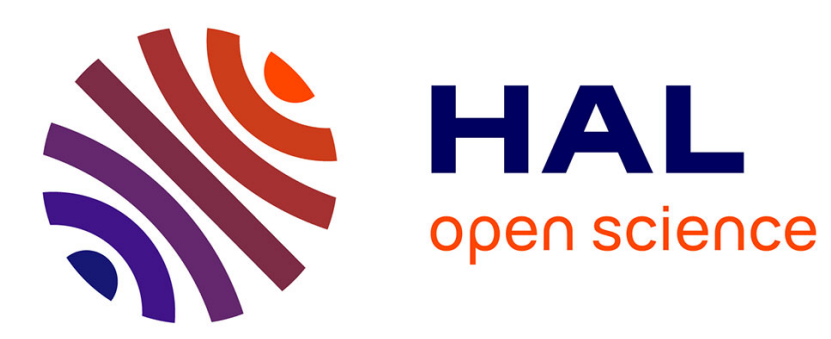

\title{
Cause-related marketing of products with a negative externality
}

Gilles Grolleau, Lisette L. Ibanez, Nathalie Lavoie

\section{To cite this version:}

Gilles Grolleau, Lisette L. Ibanez, Nathalie Lavoie. Cause-related marketing of products with a negative externality. 2016. hal-02795406

\section{HAL Id: hal-02795406 \\ https://hal.inrae.fr/hal-02795406}

Preprint submitted on 5 Jun 2020

HAL is a multi-disciplinary open access archive for the deposit and dissemination of scientific research documents, whether they are published or not. The documents may come from teaching and research institutions in France or abroad, or from public or private research centers.
L'archive ouverte pluridisciplinaire HAL, est destinée au dépôt et à la diffusion de documents scientifiques de niveau recherche, publiés ou non, émanant des établissements d'enseignement et de recherche français ou étrangers, des laboratoires publics ou privés. 


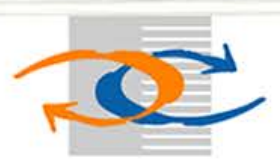

\section{A M E T A}

Laboratoire Montpelliérain d'Economie Théorique et Appliquée

\section{U M R}

Unité Mixte de Recherche -

«Cause-Related Marketing of Products with a Negative Externality»

Gilles GROLLEAU

Lisette IBANEZ

Nathalie LAVOIE

DR $n^{\circ} 2016-02$

Unite de Formation et de Recherche d'Economie

Avenue Raymond DUGRAND C.S. 79606

34960 MONTPELLIER Cedex 2

E-mail : lameta@lameta.univ-montp1.fr

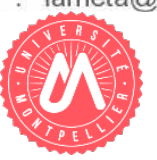

1ontp1.fr 


\title{
Cause-Related Marketing of Products with a Negative Externality
}

\author{
Gilles Grolleau ${ }^{1}$, Lisette Ibanez ${ }^{2}$, Nathalie Lavoie ${ }^{3}$
}

\begin{abstract}
Firms increasingly develop partnerships with non-profit organizations (NPO) to support a cause and improve their corporate image. This type of Corporate Social Responsibility, called Cause-Related Marketing, commits firms to fund associations that encourage environmental protection, international development, and other causes by donating part of their profits. In this article, we argue that when cause-related marketing is applied to products with a negative externality, these a priori win-win arrangements can generate adverse and unexpected effects. We consider a vertical differentiation model integrating two assumptions. First, consumers may perceive the firm's contribution to be higher than the actual donation. Second, consumers who value highly socially responsible behavior may prefer not to consume rather than consuming products that aren’t socially responsible. In this set-up we identify several possible counter-productive effects such as the likelihood of increase of the externality and the crowding out of direct contributions. We also draw policy and managerial implications.
\end{abstract}

Keywords: Cause-related products; Cause marketing; Donation; Crowding-out; Environmental externalities; Fund-raising.

JEL codes: M31

Acknowledgments: This research has been funded by the French National Research Agency (ANR-15-CE05-0008-01)

\footnotetext{
${ }^{1}$ Supagro, UMR 1135 LAMETA, 34060 Montpellier, France Université Bourgogne Franche-Comté, ESC DijonCEREN, 21000 Dijon, France

2 INRA, UMR 1135 LAMETA, 34060 Montpellier, France

${ }^{3}$ Department of Resource Economics, University of Massachusetts - Amherst, USA
} 



\section{Introduction}

In everyday shopping decisions, consumers are increasingly confronted with "cause-related” products. In cause-related marketing (CRM), firms “join with charities or 'causes' to market a product or service for mutual benefit” (Krishna, 2011). In this context, a purchase by consumers triggers a donation by the firm to a non-profit organization. Well-known examples are the Yoplait “Save Lids to Save Lives” campaign, which promises to donate 10 cents to the Susan G. Komen for the Cure foundation for each yogurt lid returned by consumers; the Endangered Species Chocolate corporation, which donates 10 percent of its net profits to environmental organizations that help endangered species; and the 'Drink 1, Give 10' campaign of the French mineral-water bottler Volvic in partnership with UNICEF, for which each liter of bottled water purchased triggers a donation equivalent to ten liters of drinking water to people in African countries. Consumers typically respond favorably to cause-related product - “80\% [of Americans] are likely to switch brands, about equal in price and quality, to one that supports a cause” (Cone, 2010). Furthermore, 47\% of consumers report frequently or occasionally purchasing products based on the causes they support (Bonetto, 2014).

These partnerships have raised significant funds for non-profit organizations and increased bottom-line profits for businesses. Although it is difficult to quantify cause-marketing spending, IEG's numbers put corporate-cause sponsorship at $\$ 1.68$ billion in 2011, predicted to grow to \$1.73 billion in 2012 (http://www.causemarketingforum.com). While the marketing and policy literatures on cause-related products are well developed and include some in depth studies on emblematic programs (e.g., Pink Ribbon, RED), purchase-triggered donation have not benefited 
from substantial attention from economists. Without purporting to be exhaustive, the marketing literature has notably investigated reasons motivating businesses and not-for-profit organizations (NPO) to engage in these partnerships and their consequences for each partner, including consumers (e.g., Varadarajan and Menon, 1988; Strahilevitz and Meyers, 1998; Berglind and Nakata, 2005). Considerable attention has been devoted to practical dimensions shaping the effectiveness of these business deals such as the 'fit' between causes and businesses (e.g., Pracejus and Olsen, 2004). From an economic viewpoint, cause-related products can be perceived as a practical and voluntary way to increase private provision of public goods. Indeed, by adding charitable causes or environmental protection to exchange, people can purchase goods that mix private and public properties ${ }^{4}$ and possibly increase their overall individual contributions to public goods provision (Kotchen, 2005, 2006).

In fact, it may be the case that cause-related products provide an "anchor price" for donations. In many donation settings people refrain from donating to charities because they have difficulties estimating a socially acceptable donation amount and fear to donate an inappropriate amount. It has been argued that decision difficulty, such as determining what an appropriate donation is in various circumstances, may lead consumers to decision deferral (Dhar, 1996). Therefore, consumers may prefer opportunities that provide them with an anchor price (Fraser et al., 1988). Briers et al. (2007) argues that a low-priced exchange product may signal a donation price that is lower than the perceived donation price in mere donation settings and may legitimize small

\footnotetext{
${ }^{4}$ A cause-related product can be defined as a bundle of private (i.e. intrinsic quality) and public (i.e. indirect donation to an NPO for a social cause or public good) attributes. Private goods are goods that are both excludable and rival in consumption, whereas public goods are neither excludable nor rival in consumption. Goods are excludable when others can be prevented from consuming the good. Goods are rival when one person's use of a good diminishes other people's use. For example, an ice cream cone is a private good, while clean air is a public one.
} 
contributions. This strategy renders most excuses for noncompliance (e.g., "We can’t afford to help.”) inappropriate and make refusal socially embarrassing. This rationale is consistent with the results of Cialdini and Schroeder (1976) who found that a reminder to potential donors that 'even a penny will help’, significantly increased the number of donations without affecting their average size. In short, the difficulty of determining the socially appropriate amount may be overcome with cause-related products where the value of the material good may play this anchoring role and signal a reference price (Briers et al., 2007 and references therein). ${ }^{5}$

Departing from the usual win-win perspective of these arrangements (but without negating it), we argue that, in some cases and for a subset of products, cause-related products can lead to adverse and unanticipated effects. While the positive effects of cause-related marketing for causes and firms and several success stories have been well documented (e.g., Basil et al., $2008^{6}$; Berglind and Nakata, 2005), we focus our analysis on the less well documented cases of causerelated marketing with adverse effects. Some unintended effects of cause-related marketing (e.g., the privatization of charities that are most attractive to consumers without being the most important ones) have been developed by Stole (2008), but the analysis is mainly conducted at a macro-level. The author argues that these practices are mainly "window dressing, a way to improve public image while detracting attention from a business's own role in undermining the public safety net.” Then if firms improve their image and increase sales of the product itself, and

\footnotetext{
${ }^{5}$ However, more research is needed to formally demonstrate that cause-related products play the role of anchor price in donations.

${ }^{6}$ As far as we know, Basil et al. (2008) is one of the studies devoted to the impact of cause related marketing on managerial issues relevant to causes. Based on a survey of 154 US non-profit organizations, they conclude 'that CRM is a positive experience for NPOs. Outcomes generally meet expectations, and drawbacks are minimal. Overall CRM appears to be a promising method for NPOs to achieve both first-order benefits (immediate financial support) and second-order benefits (less tangible goals such as developing long term relationships and public awareness).
} 
also the sale of their other products by carrying a cause-related product, consumers may be pushed to consume more than initially, leading, under some circumstances, to an increase of overall consumption: this possible effect seems to be strongly related to the kind of products (Bougherara et al., 2005). Another side effect concerns the global donations. Using experimental evidence, Krishna (2011) shows that “cause related marketing doesn’t always increase total money raised for the cause”. Buying a cause-related product is seen as a charitable act allowing consumers to buy more and donate less overall. ${ }^{7}$ When consumers care about signaling their altruistic behavior through purchase rather than through direct donations, firms may overinvest in Corporate Social Responsibility practices and related publicity, leading to lower overall donations and social welfare (Ghosh and Shankar, 2013).

In the framework developed below, we show that under some plausible circumstances, initiatives by firms to connect socially-responsible projects to their products might have negative sideeffects when the product has a socially irresponsible aspect. For example, it contributes to pollution. The positive effect of the donation can be negated, for example, by the environmental degradation that may result from an excessive purchase of the cause-related product, and by a reduction in global donations. Indeed, because of cognitive and behavioral biases, consumers can behave in ways that can lead to counter-intuitive results.

The remainder of the paper is organized as follows. In the next section, we set up a model of vertical differentiation to explore the possible effect of crowding out of donations and the possible impacts on the environment due to cause-related products. As such, our model is unique

\footnotetext{
${ }^{7}$ See also Flaherty and Diamond (1999) who show that cause marketing may reduce future direct donations because consumers "post the purchase of the product as a charitable donation expense."
} 
in three ways. First, it is adapted to a product generating a negative externality, for example, polluting. This negative quality of the product is partially offset by a donation to a charity. Thus, in this model the "high-quality" consumers, or those with a high aversion for socially irresponsible products, do not consume. Second, consumers' perception of the donation associated with the product may differ from the actual donation made by the firm. This feature accounts for the different ways to label the donations on product packages, for example, as a percent of profits or revenues, as an item donated per product, etc. Third, it considers both direct and indirect donations to charity, and allows the possibility to crowd out direct donations through the purchase of cause-related products (indirect donations). Let us stress that as with every formalized model, it does not reflect the whole and complex reality, but rather constitutes a simplified version with the purpose of identifying mechanisms that can lead to possible adverse effects. We provide anecdotal and empirical evidence supporting the relevance of our behavioral assumptions. Section 3 discusses the circumstances under which the previously identified adverse effects are more likely to arise and stresses some policy implications. Section 4 concludes and suggests directions for future research.

\section{A theoretical framework}

Cause-related (CR) products establish new relationships between three categories of agents: manufacturers, NPOs and consumers. In our model these agents have conventional constrained objective functions. Manufacturers and NPOs seek to maximize respectively profits and the cause they support under budget constraints. Consumers seek to maximize their utility under budget constraints. We assume that consumers are willing to donate for a cause for several non- 
mutually exclusive motives such as pure and impure altruism, reciprocity or commitment to social norms (Croson, 2007).

Given that one of the objectives of firms in adopting a cause is to increase profits, we model CR products as creating a vertical differentiation from rival firms. There is vertical differentiation when, at the same price, all consumers agree that a product is preferable to another. This assumption is realistic. For instance, according to Edelman’s annual Goodpurpose study, “when quality and price of a product are deemed equal, social purpose has consistently been the leading purchase trigger for global consumers since 2008, design and innovation and brand loyalty aside” (Greene, 2012). Thus, we make the assumption that at the same price all consumers prefer a CR product to an otherwise identical product that is not bundled with a donation. We model two firms, firm 1 and 2. In the benchmark scenario, both firms sell an identical standard product. In the second scenario, firm 1 bundles a cause to its product.

We assume that the product (with or without the donation) has an inherent component that causes a negative externality, that is, the product has a socially irresponsible impact on society. Of course, not all CR products have a negative impact. We focus on the most controversial subset, i.e., those products that would fit in the category that has been termed 'harmful' or “products for which consumers already have inherent negative evaluations” (e.g., a polluting product) in the CR marketing literature (Chang, 2009). In this case, the impact of the negative externality can potentially worsen if the donation creates an increase in overall consumption. In terms of negative externality, examples of products considered include products that are polluting, those that overuse renewable and non-renewable resources, and those that are harmful 
to public health. For example, CR marketing that encourages the purchase of plastic water bottles rather than drinking tap water, the purchase of small plastic containers of yogurt rather than larger ones, the purchase of paper towels rather than reusable ones, and the purchase of unhealthy products (e.g., fatty food, cigarettes, alcohol, etc.).

\section{$\underline{\text { Demand side }}$}

We set-up a modified model of vertical differentiation based on Mussa and Rosen (1978). We model consumers as maximizing the utility from a product and a numeraire good (i.e., a direct donation to a charity) subject to a budget constraint $R$. The utility function, assumed to be additively separable in the two goods, is expressed as:

$$
\max U=u(x)+u(d) \text { s.t. } R=p \cdot x+v \cdot d
$$

where $x$ is the quantity of the product, $u(x)$ is the utility derived from the product, $d$ is the quantity of the numeraire good, $p$ is the price of the product, $v$ is the price of the numeraire. The product can either be a cause-related product $x_{1}$ or a standard product $x_{2}$, and the numeraire $d$ is a direct donation to a NPO. We assume that consumers buy one unit of either the CR or standard product, that is, $x=1$, or purchase nothing. The price per unit of direct donation is normalized to 1 , that is, $v=1$. Thus, the budget constraint simplifies to $R=p+d$ and in the case of no consumption, the entire budget $R$ is directly donated to the NPO. ${ }^{8}$ In this article, we focus on the case where consumers budget a donation to charity, and where cause-related products might crowd out these direct donations. We should notice that this negative side-effect of CRM will not occur for consumers who don’t budget direct donations. ${ }^{9}$

\footnotetext{
${ }^{8}$ This formulation is similar to Ghosh and Shankar (2013) where the budget is divided between a private good, a charitable contribution and a numeraire good. We could alternatively assume that $d$ is the amount given to the NPO after income has been spent on the product in question and other goods (chosen exogenously).

${ }^{9}$ It is possible that a subset of the population does not budget for direct donations to charity. However, in the United States for example, this subset appears to be small given that $83 \%$ of Americans report having donated money to a charity during the past year (Gallup, 2013).
} 
We assume the following functional forms: $u(x)=(A-\theta \alpha) x$ where $x=1$, and $u(d)=d$. The marginal utility from consumption of the product has a component $A$ that is constant and identical for both standard and cause-related products and across consumers. However, consumers are aware of the irresponsibility of their consumption. The term $\alpha$, where $\alpha>0$, represents the extent to which the product is socially irresponsible and decreases the marginal utility of the product. ${ }^{10}$ We will also refer to a socially irresponsible product as "polluting" henceforth. $^{11}$

Consumers are heterogeneous in their aversion for socially irresponsible products. The parameter $\theta$ measures the strength of consumer aversion for the socially-irresponsible quality of good. We assume that consumers are uniformly distributed on the interval $\theta \in[0,1]$ and the total number of consumers is assumed to be one. In contrast to the typical characterization of consumer preferences of Mussa and Rosen (1978) where a positive quality is assumed, $\theta$ can be interpreted as a willingness to accept a compensation for consuming a product with negative quality. The higher the $\theta$, the higher the “compensation” needed for the consumer to buy. For example, the consumer located at $\theta=1$ has the highest degree of aversion and must experience a monetary compensation equivalent to $\alpha$ to buy a socially irresponsible product. ${ }^{12}$ The consumer located at $\theta=0$ does not care about the social responsibility of the product consumed and does

\footnotetext{
${ }^{10}$ The term $\alpha$ can be interpreted as the additional "pollution" caused by the product relative to consuming "other substitutes."

${ }^{11}$ Given the nature of our analysis devoted to harmful products (polluting ones for instance) and likelihood of adverse effects, we do not address the cases where the term $\alpha$ is nil or negative, which would represent the extent to which the product is socially responsible and increases the marginal utility of the product. While this analysis is possible in the context of our model, we choose to focus our analysis on the most controversial cases where causes are tied to harmful products.

${ }^{12}$ In this model, “compensation” takes the form of a lower price and/or a CR-marketing donation.
} 
not need to be compensated. Various works, in economics, psychology or consumer behavior, explain the existence of such responsible behavior by consumers through altruistic or otherregarding preferences (see for example Etilé and Teyssier, 2013; Thogersen, 2008).

The indirect utility of the consumer with parameter $\theta$ takes the following form when only the standard product is available:

$$
V(p, R, \theta)=\left\{\begin{array}{cc}
R & \text { if s/he buys nothing } \\
A-\theta \alpha+R-p & \text { if s/he buys the standard product }
\end{array}\right.
$$

We consider a partially-covered market, that is, consumers with the greatest aversion for socially-irresponsible products do not buy. In this context, the consumer $\tilde{\theta}$, who is indifferent between buying a standard product or nothing at all, corresponds to: $\tilde{\theta}=\frac{A-p}{\alpha}$. Thus, consumers with $\theta \epsilon\left[0 ; \frac{A-p}{\alpha}\right]$ will buy the standard product and consumers with $\left.\left.\theta \epsilon\right] \frac{A-p}{\alpha} ; 1\right]$ will not buy the product. The demand for the standard product is thus:

$$
D(p)=\frac{A-p}{\alpha}
$$

By buying a cause-related product consumers perceive less disutility than from the standard product because the warm-glow from the indirect donation offsets, at least partly, the socially irresponsible nature of the product. As such, we model the marginal utility of the CR product as $A-\theta(\alpha-f(z))$, where $f(z)$ can be interpreted as the consumers' perception of the quality or the importance of the dollar amount $z$ donated by firm 1, that is, the firm marketing the CR product. All consumers have the same perception of the donation and the "net pollution" effect caused by 
the CR product, ${ }^{13}$ however they differ in their willingness to accept a compensation $\theta$ to consume this product. We assume that the perception of the donation only partially offsets the polluting factor, that is, $f(z)<\alpha$. Thus, the overall socially-responsible quality of the product is negative.

We make the assumption that the quality level adopted by the firm (i.e., the actual amount donated z) does not necessarily match the quality perceived by consumers (i.e., the perception of the donation $f(z)$ ) given the different presentations of the donation on product packages. In some cases, one product purchased equals one item donated, in others one product purchased results in a specific amount donated or in a percentage of profits or revenue donated. In addition, the donation can either be automatic or require an additional action for the donation to occur, for example, going on a website or mailing a proof of purchase. Businesses are so imaginative in this realm that any classification can be considered as non-exhaustive. Vlachos et al. (2011) classify CRM quantifiers into three types on the basis of previous studies and current business practice, (a) monetary specific (donating a specific amount of money for every product sold); (b) in-kind (donating an item of use for every product sold) and (c) vague monetary (donating vague, i.e., non-explicitly stated amounts). ${ }^{14}$ Our model allows the examination of the effect of three types of consumer perception of the firm's donation, that is consumers perceive the firm's donation to

\footnotetext{
${ }^{13}$ This simplifying assumption allows tractability of the model and a focus on the impact of the disutility caused by the socially irresponsible product and on the warm-glow effect of CRM that partially offsets it. With this formulation, we can examine the effects of three different types of consumer perception of the amount donated by the firm, i.e., donation at, below, or above the actual amount donated by firms. The consumer population may include several subsets of consumers heterogeneous on the basis of their perception (i.e., at, below or above actual donations). A possible and interesting extension of the model would be to account for different demands according to the various subgroups.

${ }^{14}$ As example of an in-kind donation quantifier, they give D.W. Morgan in partnership with Feed My Starving Children (FMSC) foundation, which donated six meals for every client shipment delivered in February 2011. An example of a monetary specific quantifier is General Mills-Yoplait, which partners with Susan G. Komen for the Cure in the Save Lids to Save Lives campaign, and promised to donate \$.10 to for each pink lid redeemed by December 31, 2011.
} 
be less than what is actually donated $(f(z)<z)$, the perception is equal to the donation $(f(z)=$ $z$ ), and the perception is greater than the donation $(f(z)>z)$.

The mismatch between the donation offered by the firm and the consumers' perception of the amount actually donated is well supported by several empirical investigations (Olsen et al., 2003; Pracejus et al., 2004) and anecdotal or case studies evidence (Horne, 2013; Dadush, 2010; Stole, 2008). Using a web search, Olsen et al. (2003) found that on 3414 websites with a cause-related campaign, about $70 \%$ of the formats was completely abstract in nature, $25.6 \%$ of the formats was estimable, and only $4.5 \%$ was calculable. A cap on donations also contributes to the vagueness of the donation as stressed in several contributions. When there is a cap on donations, an individual purchase may not contribute anything to the cause because once the company partner's cap is reached, the company stops contributing (Horne, 2013).

In fact, Olsen et al. (2003) review research that shows that consumers tend to overestimate donations, especially when expressed as a percentage of profits and Pracejus et al. (2004) argue that current business practices frequently encourage consumers to overestimate money donated to a cause because of vague and abstract quantifiers. Anecdotal evidence supports this view. Newsweek (2007) presents this example showing how difficult it can be for consumers to determine the amount of money going to the charity as a result of a purchase:

“How much of that \$28 for a Red Gap T shirt, for example, is actually making it into clinics and villages? Gap donates between 40 and 50 percent of its gross Red profits to the Global Fund-but that doesn't necessarily mean that 50 percent of your money is going there. Red won't reveal those numbers, but has an "impact calculator" that lets 
you see what your money can buy (a \$28 shirt provides 41 single-dose treatments to prevent mother-to-child HIV transmission). But without knowing how the company calculates profit (after accounting for production, marketing, training, etc.), it’s still unclear how many dollars are actually being sent to the Global Fund.”

According to Pracejus et al. (2004), when the claim states "a portion of the proceeds will be donated...” consumers' estimates of donation varied between $\$ 0$ and $\$ 25$ for a hypothetical $\$ 49.98$ product and between $\$ 0$ and $\$ 300$ for a hypothetical $\$ 499.98$ product (see also Horne, 2013). Similarly, Harvey and Strahilevitz (2009) highlight the different impact of two causerelated products in the personal care category:

"Avon has a Breast Cancer Crusade lip balm that comes in a pink container with a ribbon logo. One hundred percent of the proceeds from the sales of this lip balm go to the Avon Breast Cancer Crusade. In contrast, Dial had a campaign in which 10 cents per sale were donated on selected products, with a maximum total donation of only $\$ 150,000$. This obviously represents a huge difference in how much is given to the cause.” (Harvey and Strahilevitz, 2009).

A report by a consortium of 16 state Attorneys General (1999, quoted in Dadush, 2010) critically examined the implications of CRM and recommended that cause-related advertisements "accurately portray, and do not misrepresent, the actual terms of the arrangement or the true effect consumers' purchasing decisions will have on charitable contributions.” Even if these deficiencies do not apply to all cause-related products, we contend that their likelihood is sufficiently supported by empirical and anecdotal evidence to analyze them explicitly. In addition to misperceiving the real donation made, consumers are likely uncertain about the 
donation and the exact pollution generated by the products. They may be well aware of their ignorance and decide to give up on taking these issues into consideration. It is likely that some consumers will give the "pollution" the benefit of the doubt, but many more will let it benefit their own desire for the product, exhibiting the perennial self-serving bias (Pieters et al., 1998). ${ }^{15}$

Thus, the indirect utility of the consumer with parameter $\theta$ takes the following form when a cause-related and a standard product are available:

$$
V(p, R, \theta)=\left\{\begin{array}{cl}
R & \text { if s/he buys nothing } \\
A-\theta(\alpha-f(z))+R-p_{1} & \text { if s/he buys the cause-related product, } x_{1} \\
A-\theta \alpha+R-p_{2} & \text { if s/he buys the standard product, } x_{2}
\end{array}\right.
$$

We can distinguish the consumer who is indifferent between buying a standard product and a cause-related one, $\bar{\theta}=\frac{\left(p_{1}-p_{2}\right)}{f(z)}$, and the consumer who is indifferent between buying a causerelated product and no product at all, $\overline{\bar{\theta}}=\frac{A-p_{1}}{\alpha-f(z)}$. Indeed consumers who attach a high value to environmental and social issues might prefer to consume nothing to have no impact on society. However, if $A \geq \alpha-f(z)+p_{1}$ the market in the CR scenario is covered.The demand for the CR and standard products are:

$$
\begin{aligned}
& D_{1}\left(p_{1}, p_{2}\right)=\overline{\bar{\theta}}-\bar{\theta}=\frac{A f(z)-\alpha\left(p_{1}-p_{2}\right)-p_{2} f(z)}{f(z)(\alpha-f(z))} \text {, and } \\
& D_{2}\left(p_{1}, p_{2}\right)=\bar{\theta}=\frac{\left(p_{1}-p_{2}\right)}{f(z)} .
\end{aligned}
$$

The introduction of the cause-related product may allow consumers who initially refused to buy a standard product to buy as the CR product has a higher socially-responsible quality than the

\footnotetext{
${ }^{15}$ An extension for future research would be to consider different groups of consumers, e.g., those who do not value the cause-related aspect of the good but care about the pollution aspect, those who value the donation, but not the pollution aspect, those who do not pay attention to either the donation or the pollution aspect, and those who care about both the donation and the pollution aspect.
} 
standard product. We are interested in the conditions under which the increase in overall consumption of the entire product category is more likely to occur. This increase in overall consumption is especially problematic for the category of products examined in this article, i.e., socially irresponsible or polluting products. This consequence (consumption increase) and its side effects (pollution increase) are not systematic. It is possible that consumers increase the consumption of the cause-related brand without increasing consumption of the product category. In this case, a successful cause-related campaign generates a brand switch, without impacting the overall pollution generated due to product consumption. Nevertheless, the effects of causerelated marketing are not the same for all products.

Several studies argue that cause-related marketing can cause more than brand switch and lead to an increase of consumption of the product category (see Bougherara et al., 2005), especially for some kinds of products such as luxury or hedonic products. The increase in consumption at both the category and product levels can be explained by the effect of the cause-related marketing in reducing the guilt associated with the consumption of some products, such as luxury, pleasureoriented hedonic, frivolous goods (e.g., chocolate, ice cream sundae) (Strahilevitz and Myers, 1998; Strahilevitz, 1999) as well as polluting or otherwise socially irresponsible goods.

The risk of increase in consumption of the overall product category has been mentioned in several studies. Harvey and Strahilevitz (2009) and Eikenberry (2009) analyze the emblematic case of some pink ribbon products where the claims on the outside "promote breast cancer awareness and research,” while chemicals on the inside "cause the disease in the first place.”16

\footnotetext{
${ }^{16}$ Harvey and Strahilevitz (2009) give another instructive example regarding pink ribbon products. "In October 2007, Fat Bastard Wines donated 25 cents from the sale of every bottle of wine to breast cancer research, up to a
} 
Consumers may not realize that in buying a product supporting a cancer-fighting cause - perhaps even a frivolous item - they may in fact be buying a product that create the toxins and other environmental hazards that help cause cancer. In the words of Eikenberry (2009) "consumption philanthropy rarely questions the act of consuming or the environmental havoc that more and more products wreak. Did the energy used to create that Endangered Species Chocolate bar destroy another acre of rain forest, and therefore hasten the endangerment of yet another species and the warming of the planet? Was that SpongeBob Pink Pants toy really worth the petroleum-and the environmental degradation that came with extracting, refining, and transforming itthat went into it?”

\section{Supply side}

We examine two scenarios; a benchmark scenario in which both firms market the standard product at price $p$ and a CR product scenario where firm 1 adopts CRM and firm 2 continues marketing the standard product. In each scenario we consider two levels of competition, i.e., Cournot competition where firms compete in quantity and Bertrand competition where firms compete in prices. ${ }^{17}$ Without loss of generality, we suppose that marginal production costs of firms are equal to zero. We examine in turn the results under Cournot and Bertrand competition.

\footnotetext{
limit of $\$ 75,000$. Although the intake of small amounts of alcohol may have some health benefit regarding cardiovascular disease, the use of alcohol also increases the risk for developing breast cancer in a dose-dependent fashion, with an increase in risk of 9\% for each $10 \mathrm{~g}$ consumed per day. Other wineries and wine-related products also display pink ribbons, illustrating a troubling example of a poor association of the actual cause and the related product. Consumers themselves have voiced concerns about the association of questionable products bearing pink ribbons and their potential to increase the risk for breast cancer, including yogurt with possibly dangerous hormones, cosmetics with possible carcinogens, and automobiles, which produce unhealthy exhaust.”

${ }^{17}$ With or without differentiated products, Bertrand competition results in a more competitive outcome than the Cournot model. With homogeneous products, the outcome under Bertrand competition is equivalent to the perfectly competitive outcome, i.e., price is equal to marginal cost.
} 
In the Cournot benchmark scenario, two identical firms maximize their profit $(\pi)$ by choosing quantity, where $\pi_{i}=p(Q) q_{i}, i=1,2, Q=q_{1}+q_{2}$, and $p(Q)$ is the inverse demand function corresponding to equation (2). In the CR product scenario, to optimize profits, we first solve (4) and (5) for the inverse demand functions and note that firm 2 incurs no costs whereas firm 1 has to pay $z$ per unit sold to the NPO. The profit functions become $\pi_{1}=\left(p_{1}\left(q_{1}, q_{2}\right)-z\right) q_{1}$ and $\pi_{2}=p_{2}\left(q_{1}, q_{2}\right) q_{2}$. The equilibrium quantities and price for both scenarios are presented in table 1.

In the Bertrand benchmark scenario, two identical firms maximize their profit, that is, $\pi_{i}=p(Q) q_{i}$, where $i=1,2, Q=q_{1}+q_{2}$, and $p(Q)$ is the inverse demand function corresponding to equation (2). In the CR product scenario, to optimize profits, we first solve (4) and (5) for the inverse demand functions and note that firm 2 incurs no costs whereas firm 1 has to pay $z$ per unit sold to the NPO. The profit functions become $\pi_{1}=\left(p_{1}\left(q_{1}, q_{2}\right)-z\right) q_{1}$ and $\pi_{2}=$ $p_{2}\left(q_{1}, q_{2}\right) q_{2}$. The equilibrium quantities and price for both scenarios are presented in table 1 .

[Insert Table 1 here]

Table 2 and 3 present the conditions necessary for a viable equilibrium in Cournot and Bertrand competition respectively, i.e., positive price and quantities, the condition under which the market is uncovered in the benchmark scenario (i.e., some consumers do not buy), as well as the condition necessary for firm 1 to adopt CRM. We also examine in those two tables the conditions under which there is an overall increase in consumption (i.e., increase in consumption of the product category) and an increase or decrease in consumption of each product with the 
adoption of CRM. The conditions are expressed in terms of the threshold expression of $A$, the inherent utility of the product, for the condition to hold. For example, in table 2, the condition under which some consumers will not buy in the benchmark scenario is $A<3 \alpha / 2$. We label this threshold value of $A$ as $I$, that is, $I=3 \alpha / 2$. It means that to ensure that some consumers do not buy the product, the disutility brought by the socially irresponsible quality of the product, $\alpha$, must be large enough relative to $A$ to make the product unattractive for the consumers with the greatest aversion toward socially irresponsible goods.

[Insert Tables 2 and 3 here]

As shown by the last column of tables 2 and 3, the ranking of the various threshold values of $A$ in some cases depend on threshold values for $z / f(z)$, i.e., the value of the donation made by the firm to the NPO, $z$, relative to the consumers' perception of the donation, $f(z)$. On the basis of the conditions developed in table 2 and 3, tables 4 and 5 summarize the possible ranges of $A$ for viable equilibrium solutions and for firm 1 to find it profitable to adopt CRM in context of Cournot and Bertrand competition respectively.

[Insert Tables 4 and 5 here]

\section{Cause-related products: more harm than good?}

When a product has an inherent component that causes a negative externality, introducing causerelated marketing $(\mathrm{CRM})$ can lead to an increase of consumption and counter-productive outcomes such as, more environmental and/or social degradation, and/or, a decrease in total 
donations. In the following sections, we determine conditions for which these perverse outcomes are likely to occur and draw some policy implications.

The social and/or environmental impact of introducing Cause-Related products

According to Andrews et al. (2014), the existing literature on CRM "attests that CM boosts consumer liking and purchase intentions.” There are several examples suggesting an increase in consumption as a result of CRM. A recent study combining in-store shopping and on-line shopping showed that for various products cause-related message led to 'a substantial sales lift relative to the generic corporate advertisement' (Cone, 2009). For instance, the study reported a 74\% increase in actual purchase for a shampoo brand when associated with a cause. Varadaraja and Menon (1988) report the following about the cause-related marketing program launched in 1983 by the American Express Company.

"American Express promised to donate a penny to the renovation of the Statue of Liberty for each use of its charge card and a dollar for each new card issued in the U.S. during the fourth quarter of 1983. American Express had a 28\% increase in card usage over the same period in 1982 and a sizable increase in the number of new cards issued."

Another example is in the context of a field experiment with close to 12,000 consumers who were given the opportunity to buy an IMAX movie ticket. Andrews et al. (2014) report "significantly more sales purchases” in the treatment with cause marketing. More specifically, cause marketing "induced almost two times the purchase incidence" than the treatment without. 
The questions we ask is to what extent, under what circumstances, and for which types of product the dominant effect of CRM is a brand switch versus an increase in consumption of the entire product category. Our model enables us to answer these questions.

Our model considers both the change in the overall product category, i.e. $\Delta Q^{P C}=q_{1}^{*}+q_{2}^{*}-Q_{B}^{*}$ (i.e. entry of new consumers to the market) and a brand switch $\Delta Q^{B C}=q_{2 B}^{*}-q_{2}^{*}$ (i.e., number of consumers switching products). A brand switch does not change the amount of pollution in our model because the two products are identical except for CR marketing. An increase in the overall product category is a pure increase in pollution because the consumers that enter the market with CRM are consumers who were not consuming any product before. ${ }^{18}$ The actual increase in pollution or social degradation will depend on the product itself - the life cycle of some products being more damaging than others. While the magnitude of the impact is important for public policy, our focus here is to identify the conditions that will likely result in an increase in pollution or social degradation.

Using the results of Tables 2 and 4, we can examine the impact on consumption of introducing CRM. Figures 1 and 2 illustrates the impact of CRM on market shares in Cournot and Bertrand competition respectively.

Under Cournot competition, cases a., b. and d. in table 4 represent possible equilibrium solutions where firm 1 finds it profitable to use CRM. The following general observations can be made:

- There is always an increase in the consumption of the product category when it is profitable for firm 1 to adopt CRM (i.e., increase in $Q=q_{1}+q_{2}$ ).

\footnotetext{
${ }^{18}$ The numeraire in our model is a direct donation. However, as pointed out in footnote 5 , we could have let $d$ represent the amount given to the NPO after income has been spent on the product in question and "other goods." In this case, our claim of increased pollution implies that the CR product pollutes more than the average "other good."
} 
- It is profitable for firm 1 to adopt CRM when the perception of the donation is larger than the actual donation. Case $d$. contains the minimum value that the perception can take relative to the actual donation, $f(z)>1.14 z .{ }^{19}$ That is, the consumer must believe that the donation is at least 1.14 times larger than what it actually is for CRM to be profitable.

- The consumption of the CR product always increases (i.e., increase in $q_{1}$ ).

Intuitively, the increase in overall consumption occurs because the cause adds utility to the product (or decreases the "pollution" disutility) and this added value more than offsets the increase in price of the product. ${ }^{20}$ The price increases for two reasons; the additional expense caused by the donation $z$ and the softening of competition that occurs with the introduction of CRM. Under the benchmark scenario the products are homogeneous and the price competition is high. When one firm introduces CRM, the products become vertically differentiated and price competition softens, which puts upward pressure on prices.

The introduction of CRM by firm 1 affects the standard product in two different ways, i.e., either decrease or increase its consumption. In case a., when the inherent utility of the product, $A$, is relatively large $(A>V)$ and the donation is low relative to what is perceived by consumers $(z / f(z)$ low), the introduction of the CR product results in a decrease in the consumption of the standard

19 When $\frac{z}{f}<\left(\frac{\alpha-f(z)}{f(z)}\right) \frac{3(\alpha+f(z))-x(3 \alpha+f(z))}{3(\alpha-f(z))+x(\alpha+f(z))}$ and $\frac{f(z)}{\alpha} \in[0 ; 0.9282[$, we can demonstrate that $\left.\left.\left(\frac{\alpha-f(z)}{f(z)}\right) \frac{3(\alpha+f(z))-x(3 \alpha+f(z))}{3(\alpha-f(z))+x(\alpha+f(z))} \in\right] 0.5 ; 0.875\right]$, which implies that $f(z) / z>[1.14 ; 2[$.

${ }^{20}$ Several examples of CRM resulting in an increase in the product price can be found. Grolleau et al. (2011) give a specific example of a CRM arrangement, i.e., Solidaime which is an umbrella brand for various CRM products where there is a price increase of cause-related-products. In the same vein, Ndodjang et al. (2013) provide experimental evidence that donations, perceived as good deeds from firms can make consumers more tolerant to price increase. Krishna and Rajan (2009) claim that cause marketing is often associated with price increases. They point to the cause marketing campaign Red, where Gap marketed Red t-shirts for \$28, whereas other t-shirts were sold for $\$ 16.50$. 
product. In other words and as shown in figure 1, the product of firm 1 becomes sufficiently attractive with CRM that some consumers buying the standard product switch to the CR product and some consumers who were not buying the product, now buy the CR product. In the other cases, when either the inherent utility of the product is not as high (i.e., $A<V$ in case a.) or the perception of the donation relative to the donation itself is not as high (i.e., cases b. and d.), there is an increase in the consumption of the standard product. In these cases, some of the consumers who were buying the product of firm 1 prior to CRM prefer to continue buying a standard product. For those consumers, the increase in utility provided by the cause does not offset the decrease in utility brought on by the price increase, i.e., their aversion for the socially irresponsible aspect of the good $(\theta)$ is not high enough. Only for consumers with high enough degree of aversion does the increase in utility provided by CRM compensates the increase in price of product 1 . As a result, some consumers switch brands and firm 2 gains market share, i.e., there is a positive spillover from CRM to firm 2.

Under Bertrand competition, cases a. and b. in table 5 represents the viable equilibrium solutions. Unlike the Cournot model, adoption of CRM by one firm does not necessarily imply an increase in overall consumption of the product category and an increase in consumption of the CR product. The difference in result occurs because the increase in market power with the introduction of CRM is more important under Bertrand competition. Without CRM the products are homogeneous and firms exercise no market power under Bertrand competition, i.e., price is set at marginal cost ( 0 in our case). When one firm introduces CRM, the products become vertically differentiated and price competition softens, which puts upward pressure on prices. In fact, in Bertrand competition, CRM is a way for firms to gain market power, whereas in Cournot, 
CRM increases the level of market power. The results are summarized in the far right column in table 5 and explained next.

Under Bertrand competition, an increase in consumption of the product category is possible under case a.(table 5), i.e., when the inherent utility of the product $(A)$ is relatively large and consumers' perception of the donation is greater than the actual donation. The increase in consumption of the product category occurs because the increase in the consumption of product 1 (CR product) offsets a decrease in consumption of product 2 . That means that some consumers, who were consuming product 2 and some who were not buying anything prior to CRM, switch to consuming the CR product once CRM is adopted by firm 1 (see figure 2). There is a switch in consumption toward the CR product.

If the inherent utility of the product is not high enough (case a., $A<I V$ ), or if the perception of the donation is lower (and potentially lower than the actual donation, case b.), it may still be profitable for firm 1 to adopt CRM even though there is a decrease in the consumption of product 1 with CRM and an overall decrease in consumption of the product category. It is still profitable for firm 1 to adopt CRM because of the market power it affords, i.e., the decrease in quantity sold is more than offset by the increase in price. In this case, the decrease in consumption of the product category occurs with a decrease in consumption of product 1 that more than offsets an increase in consumption of product 2. That means that of those consumers who were buying product 1 in the benchmark scenario, once CRM is adopted some do not buy the product anymore and some switch to the standard product (figure 2). Here, there is a switch in consumption away from the CR product. 
In summary, an increase in overall consumption of the product category, and thus a possible increase in "pollution," can occur as a result of the adoption of CRM by one firm and under the following conditions (not all must hold at the same time, refer to table 4 and 5):

- A large enough inherent utility of the product.

- The perception of the donation is large relative to the actual donation, i.e., small $z / f(z)$.

- A small increase in market power or CRM is not the only source of market power.

Increase in consumption of the product category occurs because new consumers are drawn to the market by the cause bundled to the product. However, for this to occur, our results show that valuation of the product $(A)$ by consumers, independent of the socially irresponsible quality, must be high enough for more consumers to buy the product when the CR product is introduced. This result occurs because in equilibrium, as $A$ increases the market share of the CR product rises faster than the market share of the standard product (i.e., $\partial q_{1}^{*} / \partial A>\partial q_{2}^{*} / \partial A>0$ ); consumers reluctant to buy a polluting product are drawn to the market with a CR product. Thus, products with a higher $A$ are more likely to experience an increase in consumption and cause an increase in pollution when they are bundled with a donation. In fact, Cone (2010) showed that increase in sales due to cause-related marketing are far from identical across products. Along the same line, all products are not likely to be over-consumed alike (Bougherara et al., 2005).

Moreover, condition $I V$ in Bertrand competition for increase in overall consumption of the product category decreases with a decrease in $\alpha / f(z)$ (see table 3). In other words, the more the donation is perceived by consumers to offset the polluting aspect of the product, the more 
attractive the product is to consumers with a high aversion for socially irresponsible products and the more likely an increase in consumption will result.

The results demonstrate the importance of the consumers' perception of the donation versus the actual amount donated by the firm, that is, $z / f(z)$. While it may be profitable for the firm to introduce profitably a CR product when the perception of the donation is less than the actual donation (i.e., when competition is high without CRM, as in Bertrand competition), an increase in overall consumption of the product category cannot occur unless consumers perceive the donation to be greater than its actual value (at least greater than $1.14 z$ in Cournot, and at least greater than $z$ in Bertrand). This result is reinforced by our earlier observation that firms often don't communicate clearly the amount donated and that this lack of clarity can be strategic. While $f(z)$ is exogenous to our model, we show that equilibrium Cournot profits of firm 1 rise with $f(z)$ (for a given $z$ ), and thus it is in the interest of firms to influence positively consumers' perception of the donation.

Our results also show that the level of competition before and after the introduction of CRM is important in determining whether an increase in overall consumption of the product category occurs. If CRM provides an important increase in market power, such as in Bertrand competition with homogeneous products in the benchmark scenario, the increase in price of the CR product may overwhelm the increase in utility provided by the cause. As a result some consumers may stop buying the product entirely and some consumers may switch to the standard product resulting in a decrease in overall consumption of the product category and decrease in “pollution.” Thus, practically, CRM may cause a decrease in consumption of the product 
category when different brands of a product are considered nearly perfect substitutes by consumers. Alternatively, increase in consumption of the product category is more likely to occur with market power already present in the market such as when there are few competitors or brands are viewed as differentiated by consumers.

We have demonstrated the conditions under which an increase in consumption of the product category is possible and whether consumers already buying the product switch toward or away from the CR product. Cone (2010) points out that many consumers are likely to switch from one brand to another when it is associated to a cause. Thus, an important question is the extent to which CRM brings to the market more consumers and to what extent it results in brand switching.

In what follows, we examine the cases that are characterized by an increase in consumption of CR product and the product category and compare the size of the brand switch - when the switch is toward the CR product - with the size of the increase in new consumers. Thus, the cases of interests are case a. with $A>I V$ under Bertrand competition and case a. with $A>V$ under Cournot competition. ${ }^{21}$ We want to determine the most important contributing factor of an increase in consumption of the CR product (and also an increase in consumption in the product category), i.e., the size of the brand switch, $q_{2 B}^{*}-q_{2}^{*}$, versus the size of the increase in new consumers, $\overline{\bar{\theta}}^{*}-\theta_{B}^{*}$. Under Cournot competition, we can demonstrate that the dominant explanation for an

\footnotetext{
${ }^{21}$ Note that in the other Cournot cases, the increase in new consumers must offset the loss of consumers to firm 2 (brand switch away from the CR product) for the consumption of product 1 to increase once associated to a cause.
} 
increase in consumption of the CR product is the entry of new consumers in the market. ${ }^{22}$ Under Bertrand competition, we can demonstrate that the dominant explanation for an increase in consumption of the CR product is consumers switching from the standard product to the CR product. ${ }^{23}$ Under Cournot competition, firm 1 gains mostly by attracting new customers to the market, whereas under Bertrand competition it gains mostly from attracting consumers of firm 2. When a product with a socially irresponsible component is marketed, the new customers entering the market are those who have the highest aversion toward pollution. Thus, to convince those consumers to enter the market, the perception of the donation must be sufficiently high. Indeed, in the Cournot model, minimum value of $f(z) / z$ is higher than under Bertrand. In other words, for CRM to be profitable, firms must work harder to influence positively the consumers’ perception of the donation than under Bertrand. As a result if they are successful, the dominant effect of the adoption of CRM is the entry of new consumers to the market rather than a switch in brand. ${ }^{24}$ Under more intense competition, as demonstrated in the Bertrand model, the opposite occurs with the dominant effect of the adoption of CRM being the switch in brand rather than the addition of new consumers to the market.

The impact on the global amount of donations

Relating a cause to a product allows the collection of indirect donations. A contrario, as consumers devote already a part of their budget to direct donations, the consumption of CRP

\footnotetext{
${ }^{22}$ The brand switch is smaller than the overall increase in consumption of the product category if $A>I I$ where $I I=\frac{2 \alpha z}{\alpha+f(z)}$ (see table 2). This condition always holds for feasible Cournot equilibria.

${ }^{23}$ The brand switch is larger than the overall increase in consumption of the product category if $A>I V$ where $I V=\frac{2 \alpha^{2} z}{f(z)(\alpha+f(z))}$ (see table 3). This condition holds for the case under consideration in Bertrand equilibrium.

${ }^{24}$ Under Cournot, the size of the increase in the overall consumption is positively related to $f(z)$. Increase in overall consumption is equal to $q_{1}^{*}+q_{2}^{*}-Q_{B}^{*}$. We can show that $\frac{\partial q_{1}^{*}}{\partial f(z)}>0, \frac{\partial q_{2}^{*}}{\partial f(z)}<0$, and $\frac{\partial q_{1}^{*}}{\partial f(z)}>\frac{\partial q_{2}^{*}}{\partial f(z)}$ given that condition II must hold in equilibrium.
} 
changes their direct donation decision. Donations to the NPO are the numeraire in our model. Thus, prior to the introduction of the CR product, consumers who buy nothing donate $R$ and consumers who buy the product donate $R-p_{B}^{*}$, that is, total donations before the introduction of the CR product are $\left(1-Q_{B}^{*}\right) R+Q_{B}^{*}\left(R-p_{B}^{*}\right)=R-p_{B}^{*} Q_{B}^{*}$. Following the same logic, donations after the introduction of the CR product are $-p_{1}^{*} Q_{1}^{*}-p_{2}^{*} Q_{2}^{*}+z Q_{1}^{*}$. Thus, for the overall donations to be reduced, the following must hold:

$$
z q_{1}^{*}+p_{B}^{*} Q_{B}^{*}<p_{1}^{*} q_{1}^{*}+p_{2}^{*} q_{2}^{*} .
$$

In Appendix I we show that this inequality holds in Cournot competition for all values of $A$ when $\alpha / f(z) \in] 1 ; 2[$. In other words, global donations decrease for all value of $A$ when consumers perceive the firm's donation to offset at least half of the socially-irresponsible quality of the product. We show in Appendix I that this is a necessary but not sufficient condition for global donation to decrease as there may also exist values of $A$, when $\alpha / f(z)>2$, that satisfy equation (6).

The importance of the consumers' perception of the donation is also highlighted in the result above. The higher is consumers' perception of the donation, the more likely it is that decrease in direct donations will be under-compensated by indirect donations, leading to a decrease of overall funds raised by the NPO. This crowding out of donation is likely given that, most of the time, indirect donations are relatively small compared to direct donations (Briers et al., 2007). Often, the exact amount pledged to the cause supported by the NPO is not clearly communicated to consumers or 'exploit' the consumer inexperience in computing it (e.g., 'for each product sold, 
a tree is planted' or 'a portion of the proceeds will be donated') (Pracejus et al., 2004). Thus, the higher is the consumer's perception of the donation relative to the actual amount donated and the higher the perception of the "pollution damage" that is offset by the donation in the mind of consumers, the higher the likelihood of crowding out of direct donations.

Under Bertrand competition, the inequality (6) always holds because price is equal to marginal cost (i.e., zero in our case). This result is expected given the feasible equilibria under Bertrand (table 5). Recall that under Bertrand competition, CRM results in product differentiation and a way for a firm to obtain market power. The increase in prices, and the loss of direct donations as a result, is not compensated by the cause-related donations. Thus, we conclude that for products characterized by a socially irresponsible feature and sold in markets that are highly competitive and/or characterized by low product differentiation, CRM is more likely to result in crowding out of donations if consumers view the CR product as contributing to the overall donation to NPOs.

The above reasoning does not mean that all consumers will systematically reduce direct donations because of purchase of cause-related products. As stressed before, we use simplifications to make the model tractable and the mechanisms more identifiable. The reality is more complex and at least four situations can emerge corresponding to three types of consumers with an uncertain overall effect. First, some consumers may consider direct donations and the purchase of cause-related products as two independent decisions. Second, some consumers may consider the purchase of a cause-related product as contributing to their need to donate. Third, cause-related products and direct donations can generate synergies at the consumer level (see Gneezy et al., 2012). Fourth, some consumers may not budget for direct donations, yet may buy 
CR products. Our analysis emphasizes the second case, because it corresponds to the situation most likely to lead to adverse effects for the cause, which have been documented. For instance, Flaherty and Diamond (1999) found that cause-marketing campaigns impede future donations to charities because consumers think that their purchases are donations (see also Lichtenstein et al., 2004 and Eikenberry, 2009). Moreover, even if it is not systematic, some practitioners and experts recommend discriminating consumers and to solicit, in cause-related campaigns, consumers who are not yet direct donators (du Halgouet, 2010).

\section{Discussion and Implications}

In sum, we have shown that initiatives by firms to connect socially-responsible project to their products may have potential negative side-effects in some circumstances when the product is characterized by a socially irresponsible feature: the positive effect of the donation can be negated through an increase in consumption of the entire product category leading to environmental degradation (for example) and through a reduction in global donations. The crowding-out effect may apply to the overall budget devoted to various causes and an increase in donation to a cause can imply a disproportionate decrease in donation for other causes. In addition, the crowding-out effect may be particularly strong if cause-related products are directed at consumers who were previously offering direct donations. Several parameters can help in estimating the potential effects of cause-related products on overall funds raised, such as the proportion of 'direct' donors in the whole population, the average donation amount and the donors' sensitiveness to crowding out. 
A natural managerial implication for NPOs, in their association with for-profit firms, is to negotiate optimal contracts between firms and NPOs (i.e., defining the type of indirect donation by the firm and the communication of the donated amount to consumers) in order to reduce the likelihood of a decrease in the overall donation collected. Moreover, NPOs could also target consumers who are not direct donors. Rather than adopting a one-size-fits-all strategy, companies and NPOs may need to negotiate which subsets of the population cause-related products should target in order to avoid a crowding-out effect (du Halgouet, 2010). We have assumed that the efficacy of funds collected directly or through the manufacturer are identical. If it is not the case, the analysis becomes more complex. In some cases, there is small overlap between direct contributors and the large number of potential contributors through cause-related products. Therefore, the potential loss due to crowding out may be more than offset. Lastly, designers of these partnerships have to be cautious and consider their possible effects over time, given that crowding-out can last, even after stopping the operation and be contagious to other non-targeted domains (e.g., Gneezy and Rustichini, 2000).

Consequently, one potential area of action for policymakers would be in the labeling of causerelated products. While accurate labelling is undoubtedly beneficial to consumers generally, our results show it is especially important when the product has a socially irresponsible component because inaccurate labeling can have adverse effect on the environment and on the level of donations to NPOs. Our results suggest that the more consumers perceive the donation to be important (and, in fact, greater than the actual amount donated by the firm to the NPO) 1) the more likely there will be an increase in consumption of the overall product category, which potentially generates environmental degradation or other negative socio-economic impacts, 2) 
the greater will be the increase in consumption, and 3) the more likely there will be a crowdingout of donations to the NPO. Thus, labeling that portrays accurately the dollar impact of the product purchase on the cause will contribute to mitigate these effects. In fact, the state of New York is currently examining such policy. ${ }^{25}$ In the same vein, there is a recent increase in regulatory proposals to make cause-related arrangements more transparent and accountable to all involved parties (e.g., Dadush, 2010; Horne, 2013).

\footnotetext{
${ }^{25}$ http://www.charitiesnys.com/cause_marketing.jsp. Accessed on June 17, 2014.
} 


\section{Conclusion}

Departing from the conventional or popular wisdom that cause-related products are a win-winwin strategy, we showed that, under some circumstances, they can lead to counter-productive results when the product in question is one with a socially irresponsible feature. Environmental degradation (or other detrimental and counterproductive effects in other domains such as health or poverty alleviation) may occur as well as a decrease in the efficacy of NPOs as a result of lower funds. These outcomes can be due to various combinations of several effects, namely increase in consumption of the entire product category, crowding-out of direct donations and the labeling of cause-related products that confuse consumers and create an inflated perception of the donation. The market power of firms within a same product category is also an important feature for the occurrence of negative side effects after introduction of CRM. Our results show that the increase in consumption of the product category and increase in "pollution" is more an issue when CRM is introduced in a market without a high level of competition, i.e., a market with few competitors or with some brand allegiance. While the positive effects of cause-related marketing for causes and firms and several success stories have been well documented, we argue that they deserve more academic attention, especially on dimensions that can appear as minor features but can generate first-order effect.

Designing effective cause-related products is a complex task requiring a deep analysis of interactions between several parameters such as the impact of indirect donations on products price, the environmental impact of products, and the pre-existing behavior in terms of donations. Our modeling is parsimonious and can be extended in various directions. For example, natural 
extensions include studying the optimal donation amount $(z)$ and donation labels that influence consumers' perception $(f(z))$ from the point of view of both NPOs and firms using cause-related marketing. Another extension includes relaxing the assumption that consumers differ only in their level of aversion for the socially irresponsible aspect of the product. For example, consumers may differ in the perception of the donation and on the way they allocate money to charities.

Our results suggest that one potential area of action for policymakers would be in the labeling of cause-related products. Current labels may create a different, and often inflated, perception of the actual amount donated by the firm to the NPO as a result of consumers' purchase. Labeling that portrays more accurately the dollar impact of the product purchase on the cause would contribute to mitigate the potential negative effects of cause-related products when they are characterized by a socially irresponsible feature. Standardization of cause-related claims could also help inform consumers more accurately but this mechanism itself is not immune to deficiencies. 


\section{Appendix I}

Global donations decrease if:

$$
z q_{1}^{*}+p_{B}^{*} Q_{B}^{*}<p_{1}^{*} q_{1}^{*}+p_{2}^{*} q_{2}^{*}
$$

where:

$p_{B}^{*} Q_{B}^{*}=\frac{2 A^{2}}{9 \alpha}$

$\left(p_{1}^{*}-z\right) q_{1}^{*}=\frac{[A(\alpha+f(z))-2 \alpha z]^{2}}{(\alpha-f(z))(3 \alpha+f(z))^{2}}$

$p_{2}^{*} q_{2}^{*}=\frac{\alpha(A+z)^{2}}{(3 \alpha+f(z))^{2}}$.

Substituting these expressions into equation (A.1) and rearranging we obtain:

$$
a A^{2}-b A+c>0
$$

where:

$a=19 \alpha f(z)^{2}+15 \alpha^{2} f(z)+2 f(z)^{3}$

$b=18 \alpha^{2} z(\alpha+3 f(z))$

$c=9 \alpha^{2} z^{2}(5 \alpha-f(z))$.

Note that $5 \alpha-f(z)>0$, given that we have assumed $\alpha>f(z)$.

The quadratic equation A.2 has a minimum located at $A=b / 2 a$. We can calculate the roots of a quadratic

function using the quadratic formula $A=\frac{b \pm \sqrt{b^{2}-4 a c}}{2 a}$. However, the inequality A.2 necessarily holds for all values of $A$ if $\Delta=b^{2}-4 a c<0$ (no root exist). Under this condition global donations decrease for all values of $A$.

In what follows, we examine the values of $\alpha$ and $f(z)$ that result in $\Delta<0$. Given that $\alpha>f(z)$, let $f(z)=\delta \alpha$ where $\delta \in[0 ; 1]$. We replace that expression into $a, b$, and $c$, which are substituted into and $b^{2}-4 a c$ to obtain $b^{2}-4 a c=36 z^{2} \alpha^{6}\left[9-21 \delta+\delta^{2}+9 \delta^{3}+2 f \delta(z)^{4}\right]$. Thus, $\Delta=b^{2}-4 a c<0$ $\forall A$ iff

$$
9-21 \delta+\delta^{2}+9 \delta^{3}+2 f \delta(z)^{4}<0
$$

If equation A.3 holds, global donations always decrease for all values of $A$. The inequality A.3 holds for $\delta \in$ ]0.5; 1 , or $\alpha / f(z) \in] 1 ; 2[$. In words, global donations decrease for all value of $A$ if consumers 
perceive the firm's donation to offset at least half of the socially irresponsible quality of the product. Donations are unchanged for $\delta=0.5$ and $\delta=1$ (i.e., $\alpha / f(z)=1$ and $\alpha / f(z)=2$ ).

If $\delta \in\left[0 ; 0.5\left[\right.\right.$ (and $b^{2}-4 a c>0$ ), global donations decrease when $\frac{3 z\left[3(1+3 \delta)+\sqrt{9-21 \delta+\delta^{2}+9 \delta^{3}+2 \delta^{4}}\right]}{\delta\left(19 \delta+15+2 \delta^{2}\right)}<$ $A \leq I I I$ or when $I I \leq A<\frac{3 z\left[3(1+3 \delta)-\sqrt{9-21 \delta+\delta^{2}+9 \delta^{3}+2 \delta^{4}}\right]}{\delta\left(19 \delta+15+2 \delta^{2}\right)}$. This condition also shows that both $\alpha / f(z)$ and $z / f(z)$ have a role to play in explaining the crowding out of donation. 


\section{References}

Andrews, M., X. Luo, Z. Feng, and J. Aspara, 2014. “Cause Marketing Effectiveness and the Moderating Role of Price Discounts.” Journal of Marketing, 78:120-142.

Basil, D. Z.; Deshpande, S.; and Runte, M., 2008, The Impact of Cause-related Marketing on Nonprofit Organizations" (2008). Partnerships, Proof and Practice - International Nonprofit and Social Marketing Conference 2008 - Proceedings. Paper 21, http://ro.uow.edu.au/insm08/21

Berglind, M. and Nakata, C., 2005, Cause-related marketing: More buck than bang? Business Horizons, 48 (5): 443-453.

Bonetto, L., 2014. “Cause Marketing - US - November 2014” Mintel Report. Accessed on December 21, 2015 from Mintel Academic Database at: http://academic.mintel.com/display/679826/

Bougherara, D., Grolleau, G., Thiébaut, L., 2005, Can labelling policies do more harm than good? An analysis applied to environmental labelling schemes. European Journal of Law and Economics, 19, 5-16.

Briers, B., Pandelaere, M., Warlop, L., 2007, Adding exchange to charity: A reference price explanation. Journal of Economic Psychology, 28(1), 15-30. 
Chang, CT., 2009, Consumer Response to Harmful Products with Cause-Related Marketing: Influences of Product-Cause Fit and Product Type, Advances in Consumer Research, 36: 793794.

Cialdini, RB., Schroeder, DA., 1976, Increasing compliance by legitimizing paltry contributions: When even a penny helps. Journal of Personality and Social Psychology, 34, 599-604.

Cone, 2010. $2010 \quad$ Cone Cause Evolution $\quad$ Study. http://www.conecomm.com/stuff/contentmgr/files/0/6bc819050a7914fc99b99c205493d8bc/files/ 2010_cone_cause_evolution_study_report.pdf .

Croson, R., 2007, Theories of Commitment, Altruism and Reciprocity: Evidence from Linear Public Goods Games, Economic Inquiry, 45(2), 199-216.

Dadush, S., Profiting in (RED): The Need for Enhanced Transparency in Cause-Related Marketing, International Law and Politics, 42, 1269-1336.

Dhar, R., 1996, The Effect of Decision Strategy on Deciding to Defer Choice, Journal of Behavioral Decision Making, 9(4): 265-281.

Du Halgouet, H., 2010, Les produits partage restent l'apanage des grandes associations et des multinationales, June, 17, http://ong-entreprise.blogspot.fr/2010/06/les-produits-partage-restentlapanage.html. 
Etilé, F. and Teyssier, S., 2013, Corporate Social Responsibility and the Economics of Consumer Social Responsibility, Review of Agricultural and Environmental Studies, forthcoming.

Eikenberry, AM., 2009, The Hidden Costs of Cause Marketing, Stanford Social Innovation Review, Summer: 51-55

Flaherty K., Diamond W., 1999, The Impact of Consumers' Mental Budgeting on the Effectiveness of Cause-Related Marketing, American Marketing Association Conference Proceedings, 10: 151-52.

Fraser, C., Hite, R. E., \& Sauer, P. L. (1988). Increasing contributions in solicitation campaigns: The use of large and small anchor points. Journal of Consumer Research, 15, 284-287.

Gallup, 2013. “Most Americans Practice Charitable Giving, Volunteerism.” Accessed on December 22, 2015 at: http://www.gallup.com/poll/166250/americans-practice-charitablegiving-volunteerism.aspx

Gneezy, A., A. Imas, A. Brown, L. D. Nelson, and M. I. Norton, 2012. Paying to be nice: Consistency and costly prosocial behavior. Management Science, 58(1), 179-187.

Gneezy, U. and Rustichini, A., 2000, A fine is a price, Journal of Legal Studies, 29:1-17 
Ghosh, S. and Shankar, K., 2013, Red, White and Pink: Linking Public Good Contributions to Private Good Sales, Journal of Economic Behavior and Organization, 88: 96-108

Greene, J., 2012, Cause Marketing and the Effects, Forbes, December, 15, http://www.forbes.com/sites/chicceo/2012/10/15/cause-marketing-and-the-effects/

Grolleau, G., Ibanez, L., Mzoughi, N., 2009, Too much of a good thing? Why altruism can harm the environment?. Ecological Economics, 68(7), 2145-2149.

Grolleau, G., Ibanez, L., Moulla, S., 2011. Éléments d’analyse économique des produits partage. Revue Internationale de Droit Économique, 25 (2), 239-256.

Harvey, JA., Strahilevitz, MA., 2009, The Power of Pink: Cause-Related Marketing and the Impact on Breast Cancer, Journal of American College of Radiology, 6:26-32.

Horne, J., 2013, Pink Profiteers: Cause-Related Marketing and the Exploitation of Consumers, The George Washington Law Review, 81(1): 223-258.

Hutchison, Courtney. (2010, April 24). Fried Chicken for the Cure? ABCNews. Retrieved From http://abcnews.go.com/Health/Wellness/kfc-fights-breast-cancer-friedchicken/story?id=10458830 
Komen News, 2010. KFC Presents to Susan G. Komen for the Cure ${ }^{\circledR}$ a Check for more than \$4.2 Million: Single Largest Donation in Organization's History. Retrieved from: http://ww5.komen.org/KomenNewsArticle.aspx?id=6442452377

Kotchen, M.J., 2005, Impure Public Goods and the Comparative Statics of Environmentally Friendly Consumption, Journal of Environmental Economics and Management, 49, 281-300.

Kotchen, M.J. 2006, Green Markets and Private Provision of Public Goods. Journal of Political Economy, 114(4), 816-834.

Kotchen, M.J., 2009, Offsetting green guilt. Stanford Social Innovation Review, 7(2), 26-31

Krishna, A., 2011, Can Supporting a Cause Decrease Donations and Happiness? The Cause Marketing Paradox. Journal of Consumer Psychology, 21(3): 338-345.

Krishna, A. and U. Rajan, 2009, Cause Marketing: Spillover Effects of Cause-Related Products in a Product Portfolio. Management Science, 55(9): 1469-85.

Lichtenstein, DR., Drumwright, ME., Braig, BM., 2004, The Effect of Corporate Social Responsibility on Customer Donations to Corporate-Supported Nonprofits. Journal of Marketing, 68(4): 16-32. 
Mussa and Rosen, 1978, Monopoly and Product Quality. Journal of Economic Theory, 18, 301317.

Newsweek, 2007, The Rage over (RED), March, 13, http://www.thedailybeast.com/newsweek/2007/03/14/the-rage-over-red.html

Nillson, Rahmani, S., 2009, Cause Related Marketing, From a Swedish Retail Perspective, http://epubl.ltu.se/1402-1773/2007/140/LTU-CUPP-07140-SE.pdf

Ndodjang, P., Grolleau, G. and Ibanez, L., 2013, Do Previous Good Deeds to a Third Party Make People More Tolerant of Bad Deeds against Them? An Experimental Investigation. Economics Letters 121 (3): 364-368.

Olsen, GD., Pracejus, JW., \& Brown, NR., 2003, When profit equals price: Consumer confusion about donation amounts in cause-related marketing. Journal of Public Policy and Marketing, 22(2), 70- 180.

Pieters, R.G.M., Bijmolt, T., van Raaij, W.F., de Kruijk, M.D., 1998, Consumers' attribution of pro-environmental behavior, motivation and ability to self and others. Journal of Public Policy and Marketing, 17, 215-225

Pracejus, JW.; Olsen, G. Douglas, 2004, The role of brand/cause fit in the effectiveness of causerelated marketing campaigns, Journal of Business Research, 57, 635-40. 
Pracejus, John W., G. Douglas Olsen and Norman R. Brown, 2004, On the Prevalence and Impact of Vague Quantifiers in Cause Related Marketing, The Journal of Advertising, 32, 4: 1928.

Samuelson, W. and Zeckhauser, R. 1988, Status quo bias in decision making, Journal of Risk and Uncertainty, 1: 7-59.

Stole, I.L., 2008, Philanthropy as Public Relations: A Critical Perspective on Cause Marketing. International Journal of Communication, 2, 426-440.

Strahilevitz, M., Myers, J.G., 1998, Donations to charity as purchase incentives: How well they work may depend on what you are trying to sell. The Journal of Consumer Research, 24(4), 434446.

Strahilevitz, M., 1999, The Effects of Product Type and Donation Magnitude on Willingness to Pay More for a Charity-Linked Brand.” Journal of Consumer Psychology, 8(3):215-241.

Thogersen, J., 2008, Social Norms and Cooperation in Real-Life Social Dilemmas. Journal of Economic Psychology, 29(4), 458-472.

Varadarajan, PR., Menon, A., 1988, Cause-related Marketing: A co alignment of marketing strategy and corporate philanthropy. The Journal of Marketing, 52(3), 58-74. 
Vlachos, Pavlos A., Krepapa, Areti, Koritos, Christos D. and Tasoulis, Konstantinos, 2011, Containing CSR Skepticism: The Importance of Cause-Related Marketing Quantifiers in Consumer Attributions of Corporate Motives (July 18, 2011). Available at SSRN: $\underline{\text { http://ssrn.com/abstract=1888308 }}$ or http://dx.doi.org/10.2139/ssrn.1888308

White, K., MacDonnell, R., \& Ellard, J. H., 2012, Belief in a Just World: Consumer Intentions and Behaviors Toward Ethical Products. Journal of Marketing, 76(1), 103-118. 
Table 1. Equilibrium under Cournot and Bertrand Competition

\begin{tabular}{|c|c|}
\hline \multicolumn{2}{|c|}{ Cournot Competition } \\
\hline No CRM & Firm 1 adopts CRM \\
\hline $\begin{aligned} p_{B}^{*} & =\frac{A}{3} \\
Q_{B}^{*} & =\frac{2 A}{3 \alpha} \\
q_{1 B}^{*} & =\frac{A}{3 \alpha} \\
q_{2 B}^{*} & =\frac{A}{3 \alpha}\end{aligned}$ & $\begin{array}{c}p_{1}^{*}=\frac{(A+z)(\alpha+f(z))}{3 \alpha+f(z)} \\
p_{2}^{*}=\frac{\alpha(A+z)}{3 \alpha+f(z)} \\
q_{1}^{*}=\frac{A(\alpha+f(z))-2 \alpha z}{(\alpha-f(z))(3 \alpha+f(z))} \\
q_{2}^{*}=\frac{A+z}{(3 \alpha+f(z))}\end{array}$ \\
\hline \multicolumn{2}{|c|}{ Bertrand Competition } \\
\hline No CRM & Firm 1 adopts CRM \\
\hline $\begin{aligned} p_{B}^{*} & =0 \\
Q_{B}^{*} & =\frac{A}{\alpha} \\
q_{1 B}^{*} & =\frac{A}{2 \alpha} \\
q_{2 B}^{*} & =\frac{A}{2 \alpha}\end{aligned}$ & $\begin{array}{c}p_{1}^{*}=\frac{2(A f(z)+\alpha z)}{3 \alpha+f(z)} \\
p_{2}^{*}=\frac{A f(z)+\alpha z}{3 \alpha+f(z)} \\
q_{1}^{*}=\frac{\alpha[A f(z)+z(\alpha+f(z))]}{f(z)(\alpha-f(z))(3 \alpha+f(z))} \\
q_{2}^{*}=\frac{A f(z)+\alpha z}{f(z)(3 \alpha+f(z))}\end{array}$ \\
\hline
\end{tabular}


Table 2. Conditions for Cournot Equilibrium and Effect of CRM on Consumption

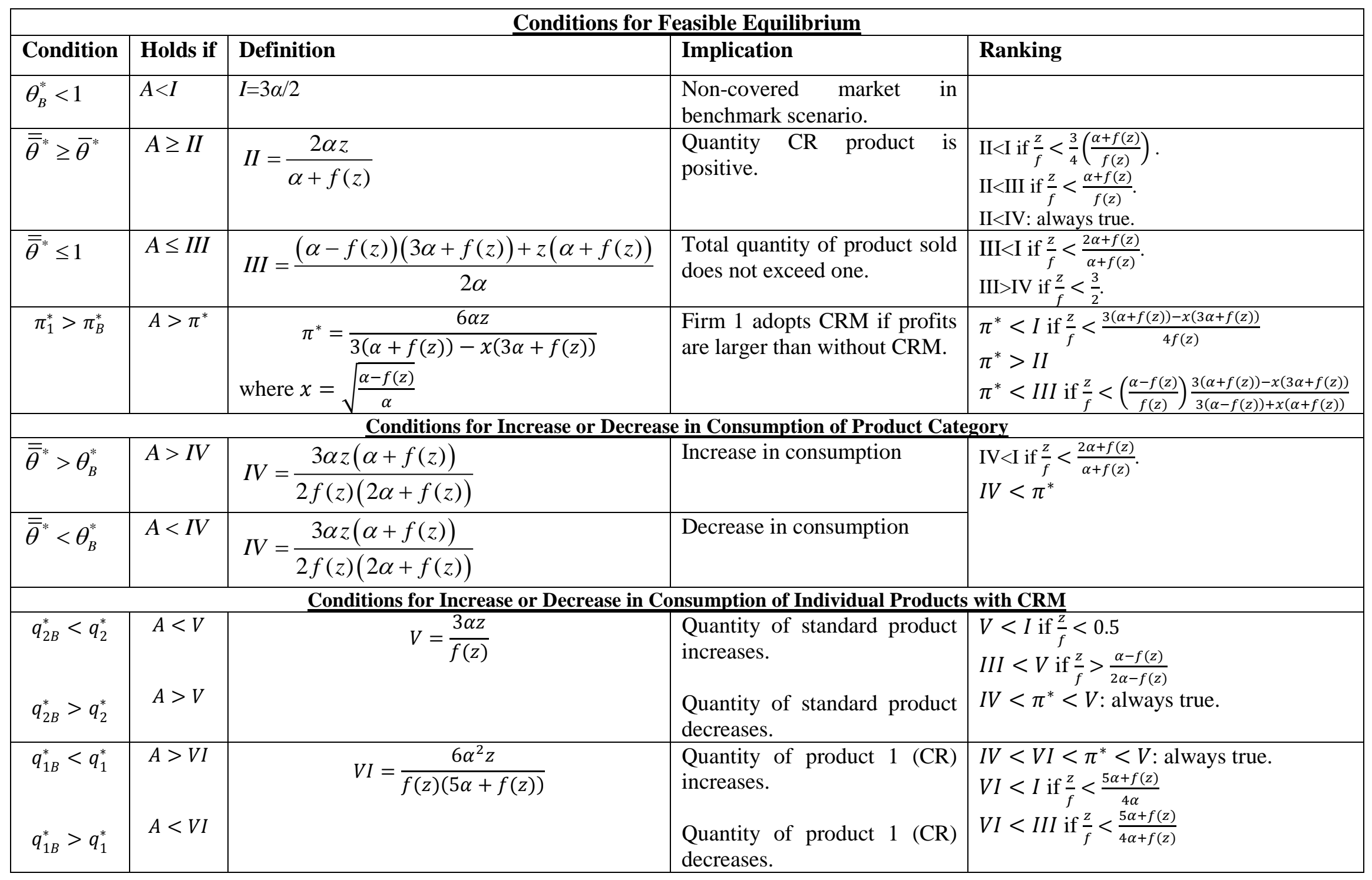


Table 3. Conditions for Bertrand Equilibrium and Effect of CRM on Consumption

\begin{tabular}{|c|c|c|c|c|}
\hline \multicolumn{5}{|c|}{ Conditions for Feasible Equilibrium } \\
\hline Condition & Holds if & Definition & Implication & Ranking \\
\hline$\theta_{B}^{*}<1$ & $A<I$ & $I=\alpha$ & Non-covered market in benchmark scenario. & \\
\hline$\overline{\bar{\theta}}^{*} \geq \bar{\theta}^{*}$ & $A \geq I I$ & $I I=\frac{z(\alpha+f(z))}{2 f(z)}$ & Quantity CR product is positive. & $\mathrm{II}<\mathrm{I}$ if $\frac{z}{f}<\frac{2 \alpha}{\alpha+f(z)}$ \\
\hline$\overline{\bar{\theta}}^{*} \leq 1$ & $A \leq I I I$ & $I I I=\frac{(\alpha-f(z))(3 \alpha+f(z))+2 \alpha z}{(3 \alpha-f(z))}$ & Total quantity of product sold does not exceed one. & $\begin{array}{l}\mathrm{III}<\mathrm{I} \text { if } \frac{z}{f}<\frac{\alpha+f(z)}{2 \alpha} . \\
\mathrm{II}<\mathrm{III} \text { if } \frac{z}{f}<2 .\end{array}$ \\
\hline$\pi_{1}^{*} \geq \pi_{B}^{*}$ & $A \geq I I$ & & Firm 1 adopts CRM if profits are larger than without CRM. & \\
\hline \multicolumn{5}{|c|}{ Conditions for Increase or Decrease in Consumption of Product Category } \\
\hline $\begin{array}{l}\overline{\bar{\theta}}^{*}>\theta_{B}^{*} \\
\overline{\bar{\theta}}^{*}<\theta_{B}^{*}\end{array}$ & $\begin{array}{l}A>I V \\
A<I V\end{array}$ & $I V=\frac{2 \alpha^{2} z}{f(z)(\alpha+f(z))}$ & $\begin{array}{l}\text { Increase in consumption } \\
\text { Decrease in consumption }\end{array}$ & $\begin{array}{l}I V<I I I<I \text { if } \frac{Z}{f}<\frac{\alpha+f(z)}{2 \alpha} . \\
I V>I I: \text { always true. }\end{array}$ \\
\hline \multicolumn{5}{|c|}{ Conditions for Increase or Decrease in Consumption of Individual Products with CRM } \\
\hline $\begin{array}{l}q_{2 B}^{*}<q_{2}^{*} \\
q_{2 B}^{*}>q_{2}^{*}\end{array}$ & $\begin{array}{l}A<I V \\
A>I V\end{array}$ & & $\begin{array}{l}\text { Quantity of standard product increases. } \\
\text { Quantity of standard product decreases. }\end{array}$ & \\
\hline $\begin{array}{l}q_{1 B}^{*}<q_{1}^{*} \\
q_{1 B}^{*}>q_{1}^{*}\end{array}$ & $\begin{array}{l}A>I V \\
A<I V\end{array}$ & & $\begin{array}{l}\text { Quantity of product } 1(\mathrm{CR}) \text { increases. } \\
\text { Quantity of product } 1(\mathrm{CR}) \text { decreases. }\end{array}$ & \\
\hline
\end{tabular}


Table 4. Definition of Possible Equilibrium Solutions under Cournot Competition

\begin{tabular}{|c|c|c|c|c|}
\hline $\begin{array}{l}\text { The re } \\
\frac{\alpha-f(z)}{2 \alpha-f(z)} \\
\frac{\alpha-f(z)}{2 \alpha-f(z}\end{array}$ & $\begin{array}{l}\text { sults below are based on } \\
<\frac{1}{2}<\left(\frac{\alpha-f(z)}{f(z)}\right) \frac{3(\alpha+f(z))-x(}{3(\alpha-f(z))+x} \\
<\left(\frac{\alpha-f(z)}{f(z)}\right) \frac{3(\alpha+f(z))-x(3 \alpha+}{3(\alpha-f(z))+x(\alpha+f}\end{array}$ & $\begin{array}{l}\text { he following inequalities (see table 2) } \\
\begin{array}{l}\frac{\alpha+f(z))}{\alpha+f(z))}<\frac{5 \alpha+f(z)}{4 \alpha+f(z)}<\frac{3(\alpha+f(z))-x(3 \alpha+f(z))}{4 f(z)}<\frac{5 \alpha+f(z)}{4 \alpha} \\
\frac{(z))}{(z))} \leq \frac{1}{2}<\frac{5 \alpha+f(z)}{4 \alpha+f(z)}<\frac{3(\alpha+f(z))-x(3 \alpha+f(z))}{4 f(z)}<\frac{5 \alpha+f(z)}{4 \alpha}\end{array}\end{array}$ & $\begin{array}{l}<\frac{3}{2}<\frac{2 \alpha+f(z)}{\alpha+f(z)}<\frac{3}{4}\left(\frac{\alpha+f(z)}{f(z)}\right)<\frac{\alpha+f(}{f(z} \\
<\frac{3}{2}<\frac{2 \alpha+f(z)}{\alpha+f(z)}<\frac{3}{4}\left(\frac{\alpha+f(z)}{f(z)}\right)<\frac{\alpha+f}{f(z}\end{array}$ & 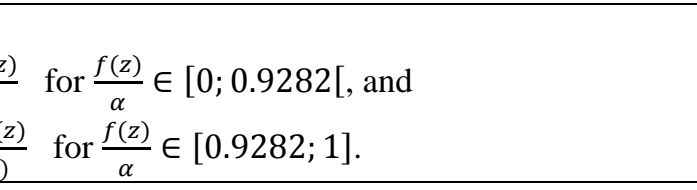 \\
\hline Case & $\begin{array}{l}\text { Ranking of Threshold } \\
\text { Values of } A\end{array}$ & Holds when & Range of Possible Solutions & Effect of CRM \\
\hline a. & $I I<I V<V I<\pi^{*}<V<I I I<I$ & $\frac{z}{f}<\frac{\alpha-f(z)}{2 \alpha-f(z)}<\frac{1}{2}$ & $\pi^{*}<\mathrm{A}<\mathrm{III}$ & $\begin{array}{l}\text { - Increase in consumption of product category. } \\
\text { - When } \pi^{*}<\mathrm{V}<\mathrm{A}<\text { III: Increase in } \mathrm{q}_{1} \text { and } \\
\text { decrease in } \mathrm{q}_{2} \text {. When } \pi^{*}<\mathrm{A}<\mathrm{V}<\mathrm{III} \text { : Increase } \\
\text { in } \mathrm{q}_{1} \text { and } \mathrm{q}_{2} \text {. }\end{array}$ \\
\hline b. & $I I<I V<V I<\pi^{*}<I I I<V<I$ & $\begin{array}{l}\frac{\alpha-f(z)}{2 \alpha-f(z)}<\frac{z}{f}<\left(\frac{\alpha-f(z)}{f(z)}\right) \frac{3(\alpha+f(z))-x(3 \alpha+f(z))}{3(\alpha-f(z))+x(\alpha+f(z))} \leq \frac{1}{2} \\
\text { and } \frac{f(z)}{\alpha} \in[0.9282 ; 1]\end{array}$ & $\pi^{*}<\mathrm{A}<\mathrm{III}$ & $\begin{array}{l}\text { - Increase in consumption of product category. } \\
\text { - Increase in } \mathrm{q}_{1} \text { and } \mathrm{q}_{2} \text {. }\end{array}$ \\
\hline c. & $I I<I V<V I<I I I<\pi^{*}<V<I$ & $\begin{array}{l}\frac{\alpha-f(z)}{2 \alpha-f(z)}<\left(\frac{\alpha-f(z)}{f(z)}\right) \frac{3(\alpha+f(z))-x(3 \alpha+f(z))}{3(\alpha-f(z))+x(\alpha+f(z))}<\frac{z}{f}<\frac{1}{2} \\
\text { and } \frac{f(z)}{\alpha} \in[0.9282 ; 1]\end{array}$ & $\begin{array}{l}\text { No CRP in feasible range } \\
(I I<\mathrm{A}<I I I) .\end{array}$ & \\
\hline d. & $I I<I V<V I<\pi^{*}<I I I<I<V$ & $\begin{array}{l}\frac{\alpha-f(z)}{2 \alpha-f(z)}<\frac{1}{2}<\frac{z}{f}<\left(\frac{\alpha-f(z)}{f(z)}\right) \frac{3(\alpha+f(z))-x(3 \alpha+f(z))}{3(\alpha-f(z))+x(\alpha+f(z))} \\
\text { and } \frac{f(z)}{\alpha} \in[0 ; 0.9282[\end{array}$ & $\pi^{*}<\mathrm{A}<\mathrm{III}$ & $\begin{array}{l}\text { - Increase in consumption of product category. } \\
\text { - Increase in } \mathrm{q}_{1} \text { and } \mathrm{q}_{2} \text {. }\end{array}$ \\
\hline e. & $I I<I V<V I<I I I<\pi^{*}<I<V$ & $\begin{array}{l}\frac{1}{2}<\left(\frac{\alpha-f(z)}{f(z)}\right) \frac{3(\alpha+f(z))-x(3 \alpha+f(z))}{3(\alpha-f(z))+x(\alpha+f(z))}<\frac{z}{f}<\frac{5 \alpha+f(z)}{4 \alpha+f(z)} \\
\text { and } \frac{f(z)}{\alpha} \in[0 ; 0.9282[\end{array}$ & $\begin{array}{l}\text { No CRP in feasible range } \\
(I I<\mathrm{A}<I I I) .\end{array}$ & \\
\hline f. & $I I<I V<I I I<V I<I<V$ & $\frac{5 \alpha+f(z)}{4 \alpha+f(z)}<\frac{z}{f}<\frac{5 \alpha+f(z)}{4 \alpha}$ & $\begin{array}{l}\text { No CRP in feasible range } \\
(I I<\mathrm{A}<I I I) \text {. }\end{array}$ & \\
\hline g. & $I I<I V<I I I<I<V I<V$ & $\frac{5 \alpha+f(z)}{4 \alpha}<\frac{z}{f}<\frac{3}{2}$ & $\begin{array}{l}\text { No CRP in feasible range } \\
(I I<\mathrm{A}<I I I) \text {. }\end{array}$ & \\
\hline h. & $I I<I I I<I V<I<V I<V$ & $\frac{3}{2}<\frac{z}{f}<\frac{2 \alpha+f(z)}{\alpha+f(z)}$ & $\begin{array}{l}\text { No CRP in feasible range } \\
(I I<\mathrm{A}<I I I) \text {. }\end{array}$ & \\
\hline i. & $I I<I<I I I<I V<V I<V$ & $\frac{2 \alpha+f(z)}{\alpha+f(z)}<\frac{z}{f}<\frac{3}{4}\left(\frac{\alpha+f(z)}{f(z)}\right)$ & $\begin{array}{l}\text { No CRP in feasible range } \\
(I I<\mathrm{A}<I I I) \text {. }\end{array}$ & \\
\hline
\end{tabular}


Table 5. Definition of Possible Equilibrium Solutions under Bertrand Competition

\begin{tabular}{|l|l|l|l|l|}
\hline \multicolumn{2}{|l|}{ The results below are based on the following inequality (see table 3), which always holds: $\frac{\alpha+f(z)}{2 \alpha}<\frac{2 \alpha}{\alpha+f(z)}<2}$. \\
\hline Case & $\begin{array}{l}\text { Ranking of Threshold } \\
\text { Values of } \boldsymbol{A}\end{array}$ & \multicolumn{1}{|c|}{ Holds when } & Range of Possible Solutions & Effect of CRM \\
\hline a. & $I I<I V<I I I<I$ & $\frac{z}{f}<\frac{\alpha+f(z)}{2 \alpha}<\frac{2 \alpha}{\alpha+f(z)}<2$ & $I I<\mathrm{A}<I I I$. & $\begin{array}{l}\text { When } I I<\text { IV }<\mathrm{A}<I I I: \\
\text { Increase in consumption of the product category. } \\
\text { Increase in } \mathrm{q}_{1} \text { and decrease in } \mathrm{q}_{2} . \\
\text { When } I I<\mathrm{A}<\mathrm{IV}<\text { III: } \\
\text { Decrease in consumption of the product category. } \\
\text { Decrease in } \mathrm{q}_{1} \text { and increase in } \mathrm{q}_{2} .\end{array}$ \\
\hline b. & $I I<I<I I I<I V$ & $\frac{\alpha+f(z)}{2 \alpha}<\frac{z}{f}<\frac{2 \alpha}{\alpha+f(z)}<2$ & $I I<\mathrm{A}<I$. & $\begin{array}{l}\text { Decrease in consumption of the product category. } \\
\text { Decrease in } \mathrm{q}_{1} \text { and increase in } \mathrm{q}_{2} .\end{array}$ \\
\hline c. & $I<I I<I I I<I V$ & $\frac{\alpha+f(z)}{2 \alpha}<\frac{2 \alpha}{\alpha+f(z)}<\frac{z}{f}<2$ & No possible equilibrium solutions & \\
\hline d. & $I<I I I<I I<I V$ & $\frac{\alpha+f(z)}{2 \alpha}<\frac{2 \alpha}{\alpha+f(z)}<2<\frac{z}{f}$ & No possible equilibrium solutions & \\
\hline
\end{tabular}


Figure 1: Impact of Cause-Related Marketing on consumption levels under Cournot Competition

Case a. with $\pi^{*}<V<A<I I I$ (as described in table 4)
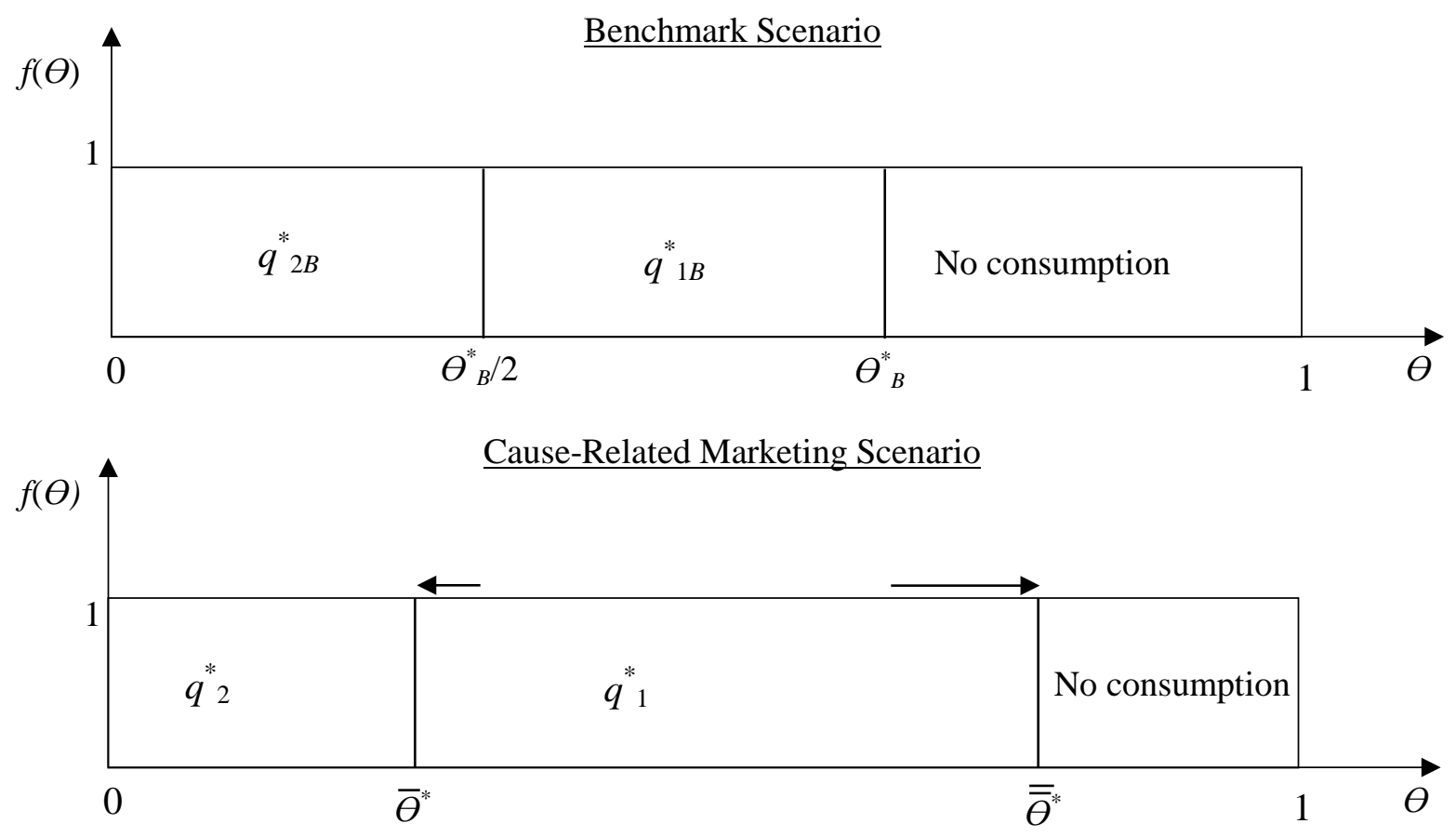

Case a. with $\pi^{*}<A<V<I I I$, case b., and case d. (as described in table 4)
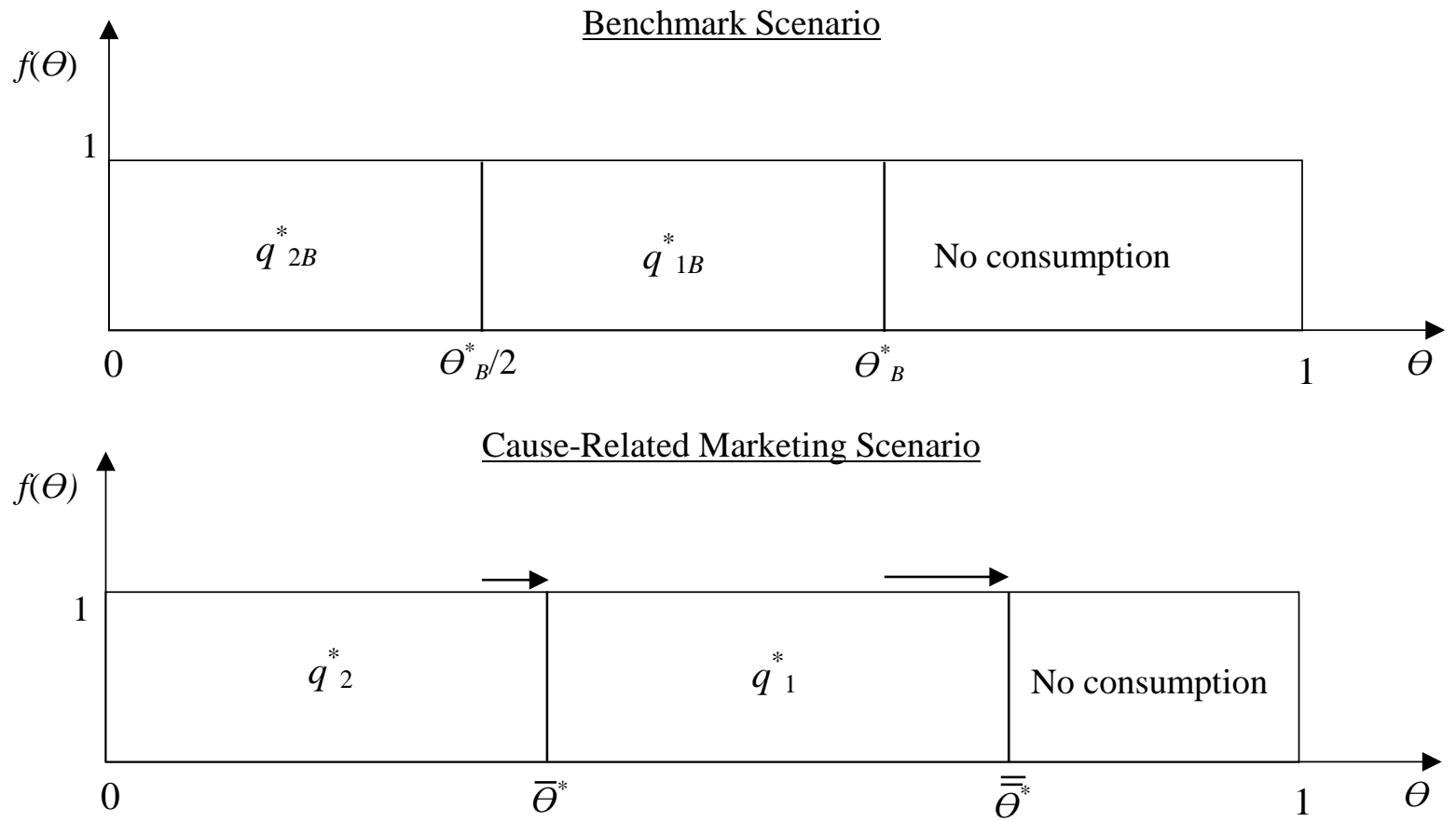
Figure 2: Impact of Cause-Related Marketing on consumption levels under Bertrand Competition

Case a. with $I I<I V<A<I I I$ (as described in table 5)
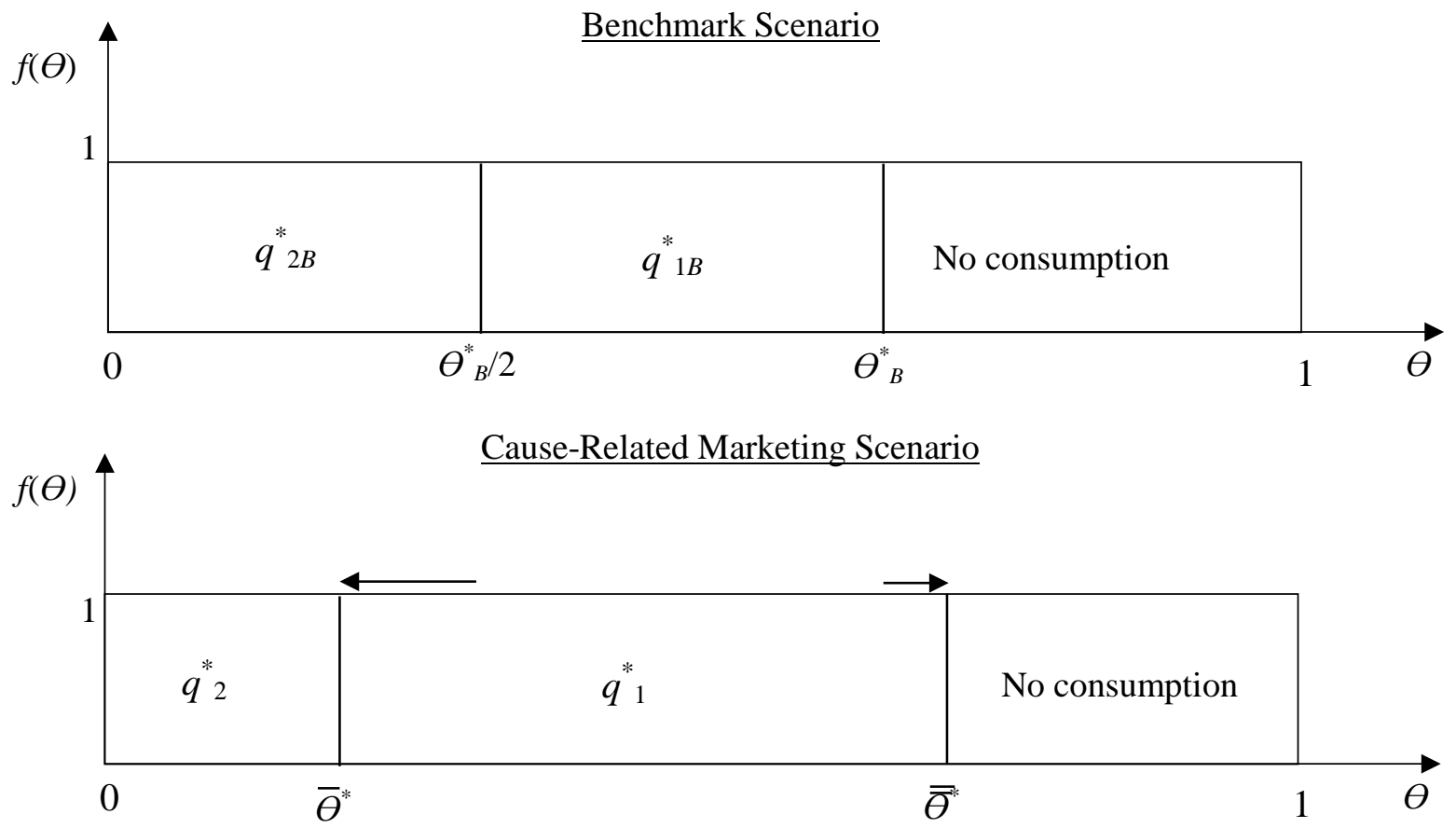

Case a. with $I I<A<I V<I I I$, and case b. (as described in table 5)
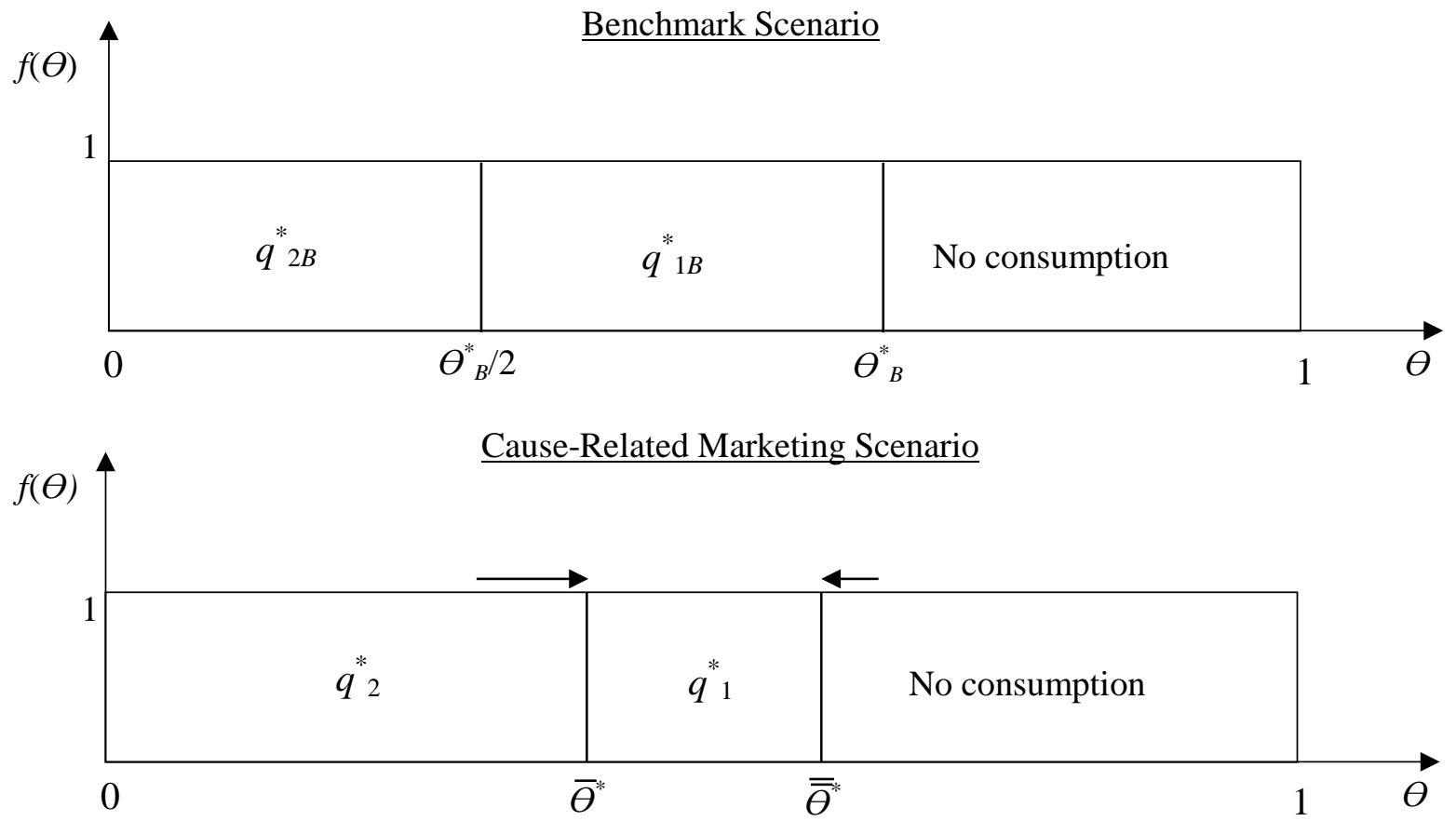


\section{Documents de Recherche parus en 2016}

DR n²016 - 01: Nicolas QUEROU, Agnes TOMINI et Christopher COSTELLO «Spatial concessions with limited tenure»

DR n²016 - 02: Gilles GROLLEAU, Lisette IBANEZ et Nathalie LAVOIE

«Cause-Related Marketing of Products with a Negative Externality » 
Contact :

Stéphane MUSSARD : mussard@lameta.univ-montp1.fr 


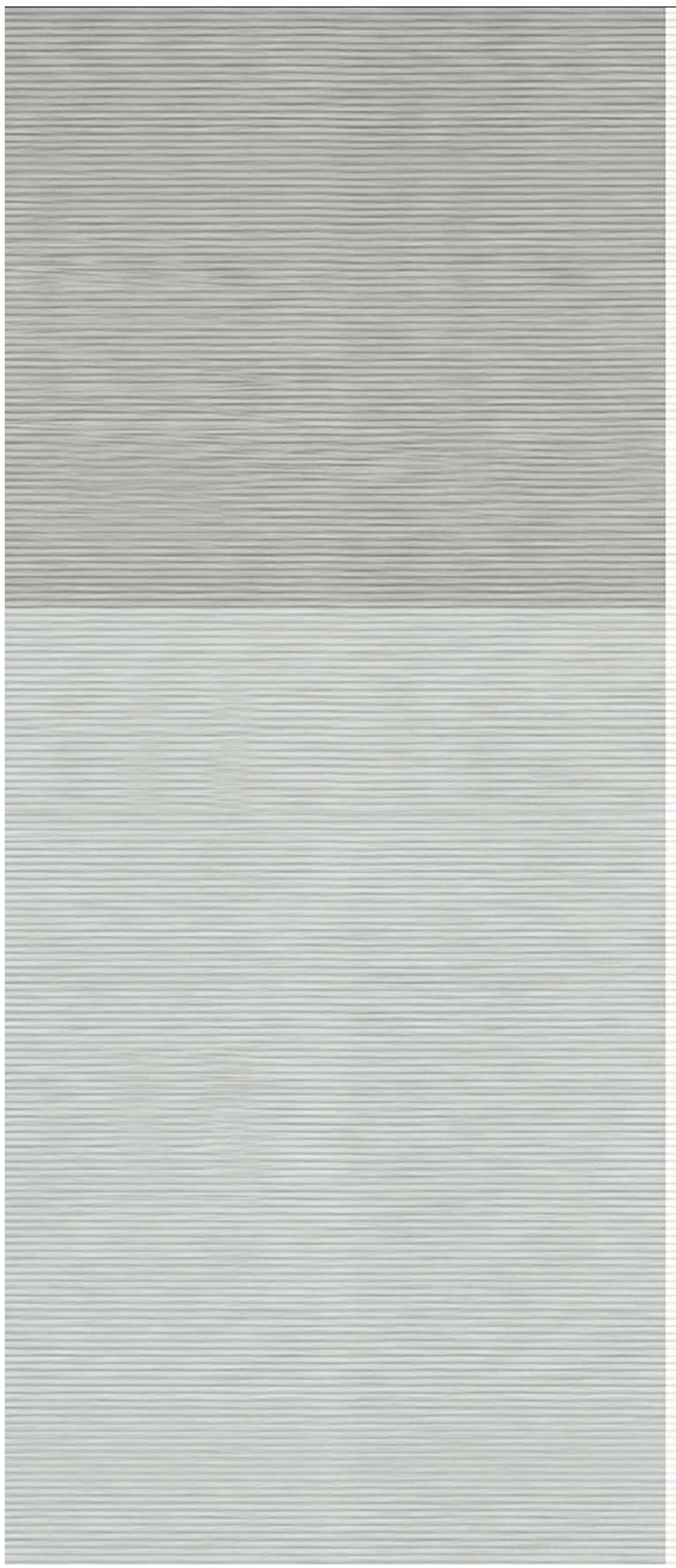

